\title{
Vitamin D interacts with Esr1 and Igf1 to regulate molecular pathways relevant to Alzheimer's disease
}

\author{
Véréna Landel ${ }^{1}$, Pascal Millet ${ }^{1,2}$, Kévin Baranger ${ }^{1}$, Béatrice Loriod $^{3}$ and François Féron ${ }^{1 *}$
}

\begin{abstract}
Background: Increasing evidence suggests a potential therapeutic benefit of vitamin D supplementation against Alzheimer's disease (AD). Although studies have shown improvements in cognitive performance and decreases in markers of the pathology after chronic treatment, the mechanisms by which vitamin $D$ acts on brain cells are multiple and remain to be thoroughly studied. We analyzed the molecular changes observed after 5 months of vitamin D3 supplementation in the brains of transgenic 5xFAD ( $\mathrm{Tg}$ ) mice, a recognized mouse model of AD, and their wild type $(\mathrm{Wt})$ littermates. We first performed a kinematic behavioural examination at 4, 6 and 8 months of age (M4, M6 and M8) followed by a histologic assessment of AD markers. We then performed a comparative transcriptomic analysis of mRNA regulation in the neocortex and hippocampus of 9 months old (M9) female mice.

Results: Transcriptomic analysis of the hippocampus and neocortex of both Wt and Tg mice at M9, following 5 months of vitamin D3 treatment, reveals a large panel of dysregulated pathways related to i) immune and inflammatory response, ii) neurotransmitter activity, iii) endothelial and vascular processes and iv) hormonal alterations. The differentially expressed genes are not all direct targets of the vitamin D-VDR pathway and it appears that vitamin $\mathrm{D}$ action engages in the crosstalk with estrogen and insulin signaling. The misexpression of the large number of genes observed in this study translates into improved learning and memory performance and a decrease in amyloid plaques and astrogliosis in Tg animals.

Conclusions: This study underlies the multiplicity of action of this potent neurosteroid in an aging and AD-like brain. The classical and non-classical actions of vitamin D3 can act in an additive and possibly synergistic manner to induce neuroprotective activities in a context-specific way.
\end{abstract}

Keywords: Vitamin D, Alzheimer's disease, Transcriptome, Nervous system, Inflammatory response, Hormonal activity

\section{Background}

The world is currently facing a global Alzheimer's disease (AD) pandemic and there is an urgent necessity to find drugs that can halt, or even better, cure this pathology. Clinicians and researchers are actively looking for molecules with neuro-protective, regenerative and immunomodulatory properties [1]. Preferably, to speed up their delivery to AD patients, the selected compounds should be FDA-approved with a well-known toxicity range.

With the intention of unveiling new molecular candidates, we elected a recognized animal model for this

\footnotetext{
* Correspondence: francois.feron@univ-amu.fr

${ }^{1}$ Aix Marseille Université, CNRS, NICN UMR 7259, Marseille 13916, France Full list of author information is available at the end of the article
}

disease, namely the 5XFAD transgenic mice [2], that exhibit mnesic deficits, increased Amyloid Precursor Protein (APP) processing and an early onset for inflammation and plaque formation [3]. We timely assessed gene misexpression in the hippocampus and neocortex of 5XFAD female mice at presymptomatic, prodromal-like and symptomatic stages of the pathology. As expected, we observed a dysregulated expression of genes involved in inflammation, NADPH oxidase complex, phagocytic processes and interferon- $\gamma$-related pathways [4]. Remarkably, we also found a modulated expression of 784 vitamin Dassociated transcripts (Additional file 1).

Vitamin D3 is a fat-soluble and seco-steroid hormone. Unlike other vitamins, vitamin D3 is mainly produced after adequate exposure to sunlight. Where this exposure 
is lacking, dietary intake of vitamin D (vitamin D2 or vitamin D3) is required. The epidermis contains a cholesterol metabolite that under ultraviolet light produces a precursor, previtamin D3. After isomerization and two separate hydroxylations, the active 1,25-dihydroxyvitamin D3 $(1,25(\mathrm{OH}) 2 \mathrm{D} 3$ or calcitriol) is produced. 1,25(OH)2D3 operates via both nuclear receptors named Vitamin D Receptor (VDR) (part of the superfamily of steroid hormone receptors) and non-genomic systems. The 1,25(OH)2D3/VDR complex interacts with specific genomic sequences named Vitamin D Responsive Elements (VDRE) found in promoter regions and has been shown to regulate the transcription of a large number (up to 1000) of target genes [5, 6].

Epidemiological and clinical data have shown that i) high serum levels of 25-hydroxyvitamin D $(25(\mathrm{OH}) \mathrm{D})$ associate with better cognitive test performance $[7,8]$ and ii) vitamin D deficiency is found in patients with Alzheimer's disease [9-13]. Other studies reported i) associations between VDR polymorphisms and cognitive function in Alzheimer's disease patients [14-19] and ii) decreased VDR mRNA levels in the hippocampus of AD patients [20].

$1,25(\mathrm{OH}) 2 \mathrm{D} 3$ has also been shown to i) enhance cerebral clearance of human Amyloid Beta $(A \beta)$ peptide from mouse brain across the blood-brain barrier [21], ii) prevent $\mathrm{A} \beta$-induced alterations in cortical neurons through upregulation of the VDR and downregulation of L-type voltage sensitive calcium channels [22, 23]. Experimental observations confirmed that i) vitamin D deficiency increases spatial learning deficits in a rat model of $\mathrm{AD}$ [24] likely by enhancing $\mathrm{A} \beta$ deposition through modulation of amyloid processing [25] and ii) vitamin D3 supplementation decreases pathological markers of the disease, such as $A \beta$ deposition, in a transgenic mouse model [26]. However, relatively little is known about the mechanisms of action of this steroid hormone in demented brains.

Purposely, we assessed the therapeutic benefit of vitamin D3 in 5XFAD mice, supplemented after the onset of the symptoms, from month 4 (M4) to month 9 (M9). Along the course of the disease, we measured memory abilities and, at the end of the experiment, we quantified amyloid plaque load. In addition, using pangenomic cDNA microarrays and bioinformatic tools, we identified the genes that were regulated, directly or indirectly, by a vitamin D3 intervention. This study is the first to provide insight into the molecular mechanisms at play after chronic treatment with vitamin D3 in both healthy aging and AD-like brains.

\section{Results}

Vitamin D3 supplementation induces an extensive gene dysregulation

To reveal the potential molecular targets of vitamin D3 in specific brain regions, we conducted a series of transcriptomic experiments. The study allowed a comparison of dysregulated genes and associated molecular pathways affected by vitamin D3 supplementation in both a non- $\mathrm{AD}$ and $\mathrm{AD}$ context, i.e. Wild-type (Wt) versus Transgenic (Tg) animals. Figure 1 reveals the total number of transcripts affected in Wt or Tg animals after 5 months of vitamin D3 supplementation. A total of 2211 genes are dysregulated in Wt animals in both the hippocampus and cortex combined, compared to a total of 1277 Differentially Expressed Genes (DEGs) in Tg mice after vitamin D3 treatment (Fig. 1a). Vitamin D3 supplementation induces a dysregulation of nearly twice as many genes in Wt animals as compared to Tg. Details about these DEGs are given in Additional file 2. There is no significant difference in terms of the number of upregulated or downregulated genes in both genotypes and brain regions (Fig. 1a). When considering each brain area analyzed, there is little difference in the number of dysregulated genes for a given genotype (Fig. 1b). In Wt mice, about $10 \%$ of DEGs are common to both tissues while $13 \%$ shared DEGs can be observed in Tg animals (Fig. 1b). Interestingly, a number of DEGs are common to both genotypes in both brain areas (Fig. 1c). Up to 366 genes are commonly dysregulated after vitamin D3 treatment in both Wt and $\mathrm{Tg}$ mice (Fig. 1d). Using Ingenuity Pathway Analysis (IPA) software, the clustering of the 366 genes indicates that among the top canonical pathways, the ones displaying the largest number of DEGs are: Axon guidance signaling (13 genes), Protein kinase A signaling (13), ILK signaling (9), Huntington's disease signaling (9), Glioblastoma Multiform signaling (8), Cdc42 signaling (8), IL8 signaling (8), Agranulocyte adhesion and diapedesis (8), Tight junction signaling (7), Embryonic stem cell pluripotency (6), Corticotropin Releasing Hormone signaling (6), Communication between innate and adaptive immune cells (5), Glutamate receptor signaling (5) and Dopamine receptor signaling (5). Furthermore, 39 out of 366 genes are associated to inflammatory response, 26 to cognition and 25 to Alzheimer's disease (Fig. 1e).

\section{An intriguing expression of hormone transcripts in the cortex and hippocampus}

One of the aims of this transcriptomic analysis was to extract information about genes whose expression is modified in the nervous system after 5 months of vitamin D3 supplementation, regardless of the pathological context. One way to obtain such information is to refine the working dataset to include only genes that are commonly dysregulated in all tested conditions. Table 1 shows the list of genes found to be dysregulated in $\mathrm{Wt}$ and $\mathrm{Tg}$ mice, in both the hippocampus and cortex. In these four conditions, we found 28 DEGs, with varying fold changes according to the genotype and brain region 


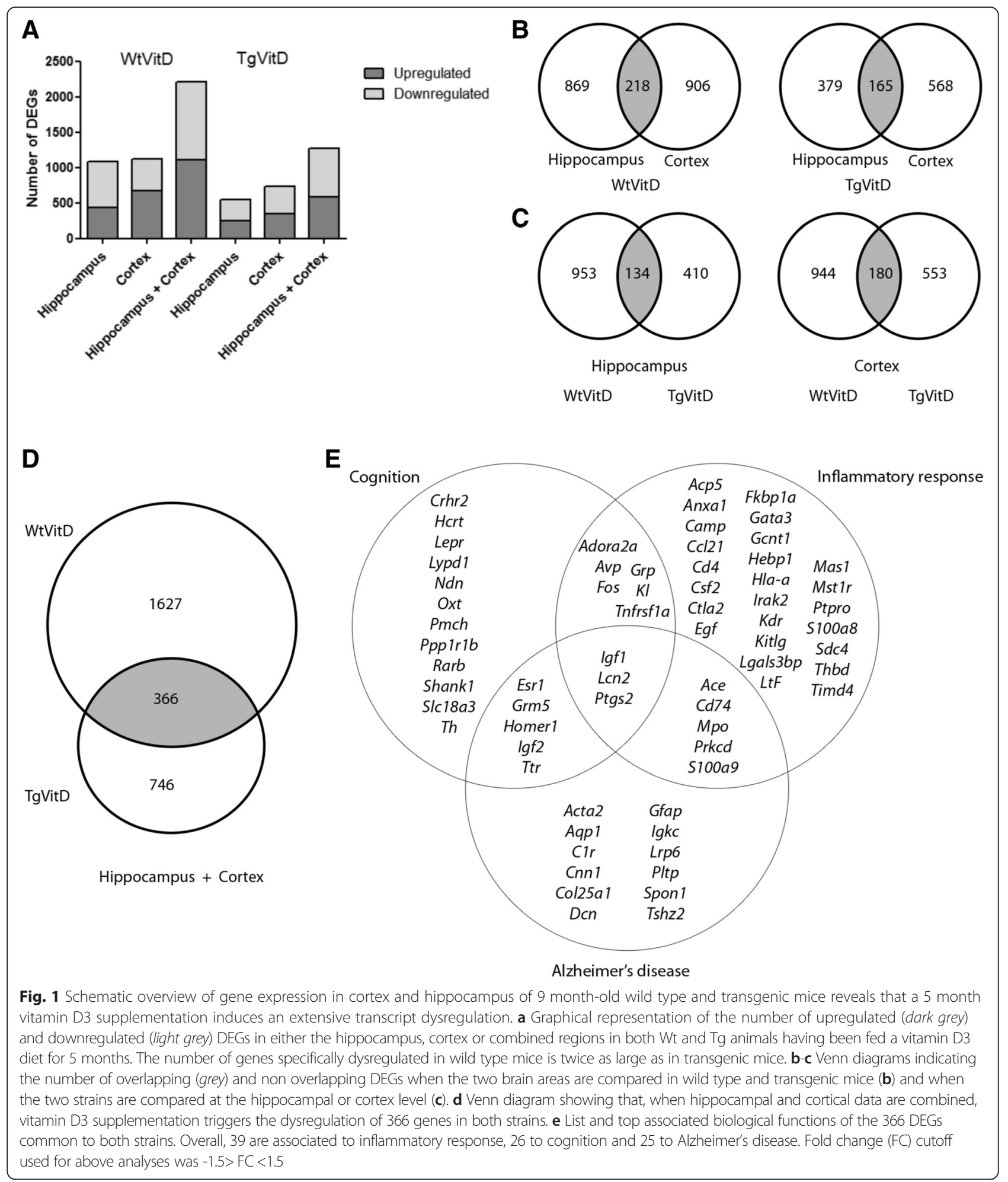

studied, that are consistently regulated after 5 months of vitamin D3 supplementation. To gain better sense of the biological functions represented by the differentially expressed genes, we performed a Functional Annotation Clustering using the NIH David tool. This analysis revealed that the genes in this dataset are related to five different biological clusters: regulation of phosphorylation, hormone activity, membrane trafficking, nucleotide binding and metal ion binding. A less restrictive additional analysis was performed on DEGs found in at 
Table 1 List of commonly dysregulated genes in the cortex and hippocampus of transgenic and wild type mice

\begin{tabular}{|c|c|c|c|c|c|}
\hline \multirow[b]{3}{*}{ Gene symbol } & \multirow[b]{3}{*}{ Entrez gene name } & \multicolumn{4}{|l|}{ Fold change } \\
\hline & & \multicolumn{2}{|l|}{ Hipocampus } & \multicolumn{2}{|l|}{ Cortex } \\
\hline & & WtVitD/Wt & TgVitD/Tg & WtVitD/Wt & TgVitD/Tg \\
\hline Ahcy & adenosylhomocysteinase & $-1,73$ & $-2,07$ & 1,79 & 2,07 \\
\hline $\operatorname{Atg} 4 \mathrm{C}$ & autophagy related 4 C, cysteine peptidase & $-2,72$ & $-2,75$ & 4,49 & 4,82 \\
\hline Avp & arginine vasopressin & $-1,59$ & 2,21 & 1,73 & 3,96 \\
\hline$C 130078 n 14$ & uncharacterized protein C130078N14 & $-2,13$ & $-2,17$ & 3,92 & 2,77 \\
\hline Cdk5rap 1 & CDK5 regulatory subunit associated protein 1 & $-1,78$ & $-2,14$ & 2,66 & 2,92 \\
\hline Cpnel & copine I & $-1,56$ & $-1,82$ & 1,6 & 1,71 \\
\hline Dnajb8 & DnaJ (Hsp40) homolog, subfamily B, member 8 & $-1,85$ & 1,98 & $-1,92$ & $-1,73$ \\
\hline Fam205a & family with sequence similarity 205 , member A & 2,34 & 2,78 & 1,61 & $-1,55$ \\
\hline Fkbpla & FK506 binding protein $1 \mathrm{~A}, 12 \mathrm{kDa}$ & 1,97 & 1,62 & $-1,72$ & $-1,52$ \\
\hline Gbp6 & guanylate binding protein family, member 6 & 2,19 & 2,21 & $-2,65$ & $-3,23$ \\
\hline Gm4924 & predicted gene 4924 & 1,68 & 1,94 & 2,14 & 1,53 \\
\hline Hla-drb5 & major histocompatibility complex, class II, DR beta 5 & 1,86 & 1,53 & $-2,53$ & $-2,34$ \\
\hline lqcf4 & IQ motif containing F4 & 2,74 & 2,22 & $-1,54$ & $-1,73$ \\
\hline lasec3 & IQ motif and Sec7 domain 3 & $-5,23$ & 4,49 & $-3,3$ & 1,58 \\
\hline Kcnj6 & potassium channel, inwardly rectifying subfamily J, member 6 & 1,61 & 1,93 & $-1,79$ & $-1,67$ \\
\hline$K d r$ & kinase insert domain receptor & $-1,6$ & 1,68 & 1,53 & $-1,64$ \\
\hline Mirg & miRNA containing gene & $-1,91$ & 1,88 & $-3,41$ & $-1,68$ \\
\hline Nanog & Nanog homeobox & $-2,91$ & 1,53 & $-1,52$ & $-1,66$ \\
\hline Ocell & occludin/ELL domain containing 1 & $-3,07$ & $-3,98$ & 3,52 & 3,21 \\
\hline Omp & olfactory marker protein & $-1,54$ & $-10,41$ & 3,18 & 1,66 \\
\hline Oxt & oxytocin/neurophysin I prepropeptide & $-2,75$ & 4,04 & 2,03 & 4,74 \\
\hline Ppp1r16b & protein phosphatase 1 , regulatory subunit $16 \mathrm{~B}$ & 2,29 & 2,39 & $-1,78$ & $-1,78$ \\
\hline Prkcd & protein kinase $\mathrm{C}$, delta & $-2,18$ & $-2,52$ & 1,84 & 1,65 \\
\hline Prl & prolactin & 1,93 & $-1,88$ & 10,07 & 10,54 \\
\hline Rnase4 & ribonuclease, RNase A family, 4 & 1,61 & 2,12 & $-2,14$ & $-2,07$ \\
\hline Sdc4 & syndecan 4 & 2,38 & 1,95 & $-1,91$ & $-1,81$ \\
\hline Serpina3g & serine (or cysteine) peptidase inhibitor, clade A, member $3 G$ & 2,78 & 1,94 & $-1,8$ & $-2,42$ \\
\hline Znf669 & zinc finger protein 669 & $-2,08$ & $-1,9$ & 1,84 & 2,2 \\
\hline
\end{tabular}

Dysregulated transcripts in the hippocampus and cortex of vitamin D3 supplemented wild type and transgenic mice in comparison with unsupplemented littermates. The gene symbol, the full name and the fold change of each gene are indicated

least three out of the four conditions. Table 2 represents the top ten biological clusters associated with this dataset. One hundred thirty-six genes were differentially expressed (Additional file 3) and when performing functional annotation clustering of these DEGs, the number one biological function is hormone activity (Table 2). Eight genes fall into this ontological category: Avp, Igf1, Igf2, Nppa, Oxt, Pmch, Prl, Trh. Bearing in mind that several of these neuropeptides are largely found in the pituitary axis, it is extremely intriguing to find them differentially expressed in the cortex or hippocampus of 5XFAD mice.

Among the top ten biological pathways affected by vitamin D3 treatment, two of them concern synaptic processes and neurotransmission with dysregulation of genes such as Syn3, Syt10 and Sv2c, while two others are related to immune responses including genes such as $C 1 q b, C d 4$ and $C d 74$ (Table 2). A literature search was then performed to determine whether some of these genes contain a putative VDRE in their sequence. Among the 136 genes commonly dysregulated, only four, Fos, Gcnt1, Irak2, St6galnac1, were found to present a known functional VDRE in their promoter region [6].

\section{The effects of vitamin D3 supplementation vary according to the health status of the animal}

To move further and comprehensively assess the effect of vitamin $\mathrm{D}$ on brain functioning, we analyzed the 
Table 2 Top ten biological clusters associated with transcripts dysregulated in at least 3 out of 4 conditions: misexpression in the hippocampus and/or cortex of transgenic and/or wild type mice

\begin{tabular}{lll}
\hline Annotation term & Number of genes & Genes \\
\hline Hormone activity & 8 & Avp, Igf1, Igf2, Nppa, Oxt, Pmch, Prl, Trh \\
Synaptic vesicle & 5 & Doc2g, Slc17a6, Syn3, Sv2c, Syt10 \\
Regulation of phosphorylation & 6 & Cd4, Cd74, Cdk5rap1, Fkbp1a, Irak2, Prkcd \\
Membrane-bounded vesicle & 8 & Capn11, Doc2g, Gpnmb, Prl, Slc17a6, Syn3, Sv2c, Syt10 \\
Striated muscle tissue development & 4 & Fkbp1a, Foxp1, Rxrg, Tnnt2 \\
Blood circulation & 4 & Acta2, Ace, Avp, Nppa \\
Lymphocyte activation & 4 & Cd4, Cd74, Fkbpla, Foxp1 \\
C2 calcium-dependent membrane targeting & 4 & Cpne1, Doc2g, Prkcd, Syt10 \\
Immune effector process & 4 & Cd74, C19b, Foxp1, Prkcd \\
Synapse & 5 & Shc4, Slc17a6, Syn3, Sv2c, Syt10 \\
\hline
\end{tabular}

Cluster name, number of genes within each cluster and acronym of each gene are indicated

record of dysregulated genes, in accordance with their role in well-described metabolic pathways. For each strain, we combined transcriptomic data from the hippocampus and the neocortex at M9 and, using Ingenuity software, we listed the main canonical pathways that were modified by the vitamin D3-enriched diet. We then compared the two strains of animals (Wt $v s \mathrm{Tg}$ ). All perturbed pathways and the names of their associated DEGs are recorded in Additional file 4. Out of the 90 major modified canonical pathways, 42 were common to both strains. As shown in Fig. 2, 16 of them are related to either the nervous or the immune system.

In regard to the brain (Fig. 2a), the largest number of dysregulated genes - 53 and 38 for the Wt and Tg animals, respectively - is associated to Axon guidance signaling. Within both strains, we observe a modified expression of growth factors (e.g. Bdnf, Bmp1, Bmp6, Egf, Igf1, Figf, Ntf3, Vegfc), chemo-attractive/repulsive agents (e.g. Sema3b, Sema3c, Sema4g, Sema6b, Sema6c), proteases (e.g. Ace, Adam11, Adamts2, Adamts8, Adamts9, Mmp9) and TGF/WNT/ $\beta$-catenin-associated molecules (e.g. Tgfb1, Tgfbr1, Tgfbr2, Wnt1, Wnt3, Wnt6, Wnt9a, Wnt9b, Wnt16). Two other metabolic pathways - the signaling of the corticotropin releasing hormone and the multiform glioblastoma - include large subsets of dysregulated genes. However, the highest ratio (number of dysregulated genes/number of genes involved in the pathway) is found for the neuroprotective role of THOP1 in Alzheimer's disease.

With respect to the immune system (Fig. 2b), three canonical pathways - Role of macrophages, fibroblasts and endothelial cells in rheumatoid arthritis, Agranulocyte adhesion and diapedesis and Dendritic cell maturation - emerge as primarily affected by vitamin D3 supplementation, in both strains. Other modified metabolic pathways include Communication between innate and adaptive immune cells, Complement system and
MIF regulation of innate immunity. Nonetheless, the peak ratios are observed for the Role of Il17F in inflammatory diseases and the role of Il17A in psoriasis.

In addition to this strain independent response to vitamin D3 supplementation, the brains display specific modifications in line with the health status of the animal. For example, vitamin D3-enriched diet modify the expression of glucocorticoid and glutamate receptors in wild type animals and GABA, dopamine and serotonin receptors in transgenic animals (Fig. 2a). Similarly, vitamin D3 alters interleukin signaling in a strain-dependent manner. IL-12 and IL-8 pathways are adjusted in Wt and $\mathrm{Tg}$ brains, respectively (Fig. $2 \mathrm{~b}$ ). Other examples of discrepancies can be listed. The non pathological brain responds to vitamin D3 treatment by modifying the expression of i) nitric oxide in macrophages, ii) neurotrophins and iii) molecules related to Huntington disease whereas the pathological brain reacts by altering the expression of iv) nitric oxide in endothelial cells, v) cathecholamines and vi) molecules associated to Multiple Sclerosis.

\section{Vitamin D3, a potent upstream regulator altering the expression of Alzheimer's disease-associated genes}

To further decipher the detailed role of vitamin $D$ in brain functioning, we narrowed our analysis to the genes that are directly or indirectly regulated by vitamin $\mathrm{D}$ or its related-metabolites. Using Ingenuity software, we listed all dysregulated molecules whose expression has been associated, in the literature, to this steroid.

As summarized in Fig. 3, we observed 290 and 249 vitamin D-related DEGs respectively, when comparing vitamin D3-supplemented Wt and Tg mice with their unsupplemented littermates. Within these two pools, 188 and 151 genes are part of the initial list of 784 vitamin D-associated transcripts whose expression is altered in the brain of transgenic animals (Additional file 5). 
Furthermore, when assessing the presence of a VDRE in the promoter region of these DEGs [6], we found 25 (13\%) and 18 (12\%) transcripts in the two above-mentioned populations (highlighted in grey in Additional file 5). As a comparison, 68 (9 \%) out of the 784 genes listed in Additional file 1 harbor a VDRE. We then clustered the two populations of vitamin D-related DEGs and, as shown on Fig. 3, we highlighted three sub-populations, composed of transcripts involved in inflammatory response, Alzheimer's disease and cognition.

At this point, we decided to validate the observed expression of certain DEGs of our dataset, using quantitative PCR (qPCR). We chose two hormones, Oxt and $A v p$, which are, according to the microarray results, dysregulated in the hippocampus and cortex of both Wt and Tg animals. We also focused on four vitamin Drelated genes involved in $\mathrm{AD}$ commonly dysregulated in the neocortex and hippocampus of $\mathrm{Tg}$ animals, namely Lcn2, Ptgs2, Esr1 and Igf1. An overexpression of the transcripts $O x t$ and $A v p$ is confirmed in the cortex as well as an upregulation of Esr1 in the hippocampus. The gene coding for $L c n 2$ is overexpressed in both the hippocampus and the cortex. However, the downregulation of Igf1 is not confirmed by qPCR analysis (Fig. 3b).

Vitamin D3 supplementation alters the expression of many Alzheimer's disease-associated genes, even in $\mathrm{Wt}$ brains. However, major differences can be observed. As reported on Fig. 4, 29 and 27 transcripts are uniquely misexpressed in Wt and Tg animals, respectively. In addition, 13 out of the 16 vitamin D-related DEGs emerging at the intersection of both strains are inversely expressed. The three transcripts that are similarly misexpressed are Ace, Igf1 and Gfap, strongly related to Alzheimer's disease. All three are underexpressed when compared to unsupplemented animals (Fig. 4).

The consequences of this discordant response to vitamin D3 treatment are unknown since the Wt mice display no AD symptoms and features. Nevertheless, it allowed us to envision the putative mechanism of action of vitamin D3 or its related metabolites (Fig. 4). Vitamin D3 or 1,25(OH)2D3 and its receptor likely act via four regulators, namely IGF1, ESR1, ERK and NF-кB. Igf1 is underexpressed in both strains while Esr1 is overexpressed in $\mathrm{Tg}$ brains and underexpressed in Wt brains. The expression of Erk and $N f-\kappa b$ is unchanged in both strains but many transcripts under their control are misexpressed in Tg and Wt animals. Downstream gene regulators include Fos, Stat1 and Stat3. The former is overexpressed in $\mathrm{Tg}$ and underexpressed in Wt animals.

\section{Vitamin D3 treatment impacts amyloid plaque load and gliosis in transgenic animals}

In order to examine whether a 5-month therapeutic intervention with vitamin D3 translated into a positive functional outcome, animals were analyzed at the histological and behavioral levels for known markers of $\mathrm{AD}$ pathogenesis. At the histological level, vitamin D3 supplementation decreased the quantity of plaques in three different brain regions of $\mathrm{Tg}$ mice: frontal cortex, hippocampus and neocortex (Fig. 5a). Astrogliosis, assessed through GFAP-immunostaining, is greatly increased in Tg animals compared to Wt. Vitamin D3 treatment of Tg animals during 5 months significantly decreases GFAP reactivity. However, this significant decrease is only observed in the frontal cortex (Fig. 5b). Microglial activation was assessed through immunostaining with IBA1 antibody and although there is an increase in this microglial marker between Wt and Tg control mice, vitamin D3 supplementation increases IBA1 immunoreactivity only in the frontal cortex of $\mathrm{Tg}$ animals when compared to their unsupplemented littermates (Fig. 5c).

\section{Four months of vitamin D3-enriched diet is sufficient to rescue cognitive deficits in the 5XFAD model}

After 4 months of vitamin D3-supplemented diet, cognitive performance was evaluated using two different paradigms: the Y-maze and the 6-radial arm water maze. A longitudinal study was first performed from M4 to M8 using the Y-maze. This study shows that $\mathrm{Tg}$ animals display a decreased percent of alternation with time whereas aging $\mathrm{Tg}$ animals on a high vitamin D3 diet do not show any cognitive decline between M4 and M8 (Fig. 5d). At M8, we observed a significant decrease in percent alternation performance in Tg mice. This effect is rescued by treatment with vitamin D3 during 4 months with no significant difference in the number of arms entered (Fig. 5e and f). However, a high vitamin D3 diet does not improve working memory in wild-type animals, even at M8 (Fig. 5e). The RAWM was used in addition to the Y-maze to assess hippocampal-dependent spatial working memory and reference memory. At the end of the learning process (end of day 3), results show a significant decrease in the total number of errors for $\mathrm{Tg}$ animals having been fed a vitamin D3 supplemented diet compared to Tg animals on a control diet (Fig. 5g).

\section{Discussion}

Despite growing evidence that vitamin D deficiency is a risk factor for cognitive decline and possibly Alzheimer's disease, very few studies have investigated the effect of vitamin $\mathrm{D}$ supplementation in AD mouse models. To our knowledge, this is the first transcriptomic study to assess the effect of long-term vitamin D3 supplementation in the nervous system of an AD mouse model. This work allowed us to examine the effects of chronic vitamin D3 treatment in both normal aging and AD-like brains, at the transcriptomic, histological and behavioral levels. We observed a very large number of dysregulated 


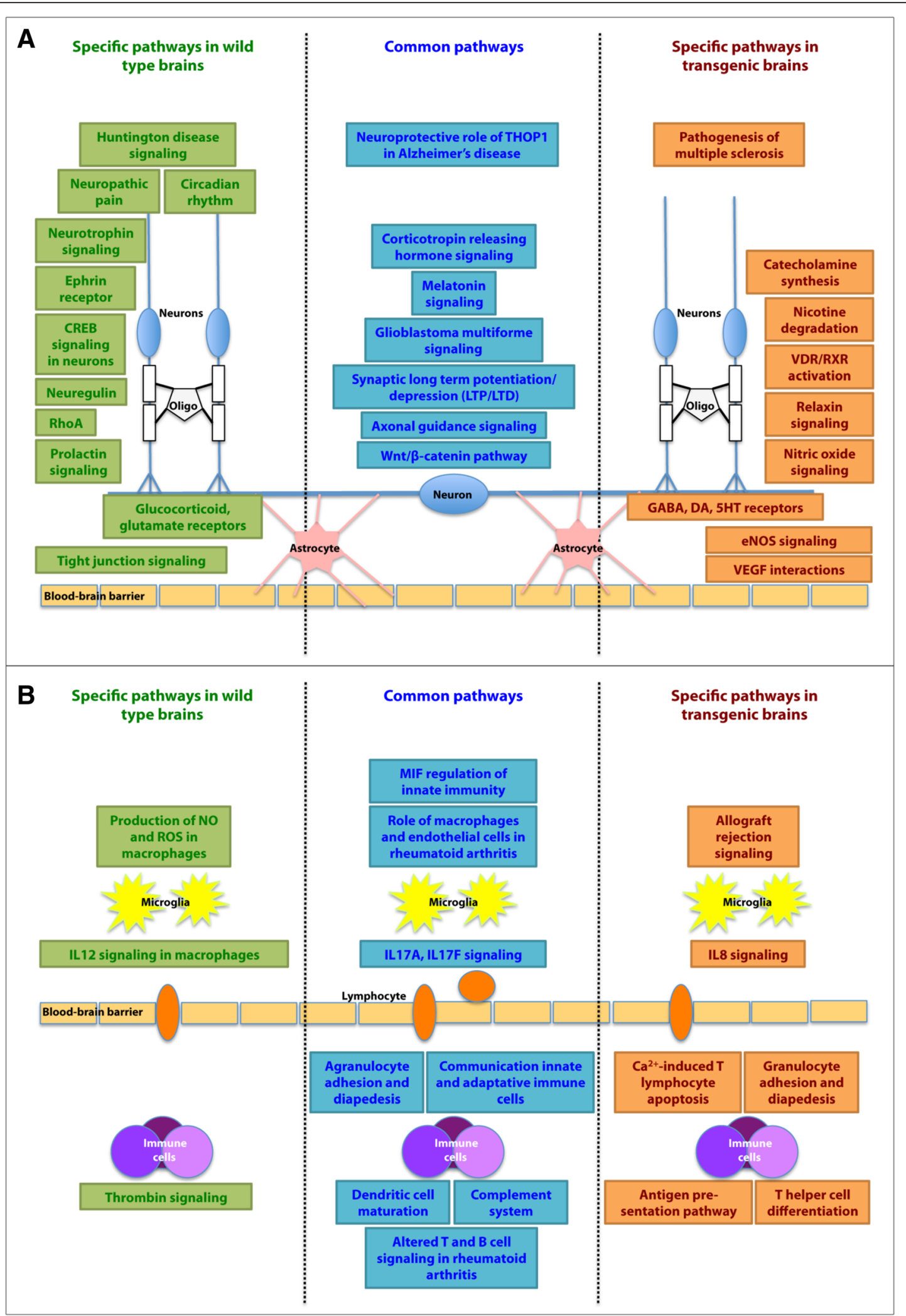

Fig. 2 (See legend on next page.) 
(See figure on previous page.)

Fig. 2 Top canonical metabolic pathways associated to gene dysregulation in the cortex and hippocampus of mice after 5 months of vitamin D3 supplementation: common versus strain-specific processes. Metabolic pathways associated to gene expression dysregulation were identified using Ingenuity Pathway Analysis (IPA). Data from both the cortex and hippocampus were analyzed as one dataset and the main metabolic pathways affected were clustered according to their association to the nervous (a) or the immune (b) system

genes in both the pathological and non AD-like cortex and hippocampus of these animals at M9. On the one hand, our results point out that, although there are nearly double the number of DEGs in Wt animals compared to $\mathrm{Tg}$, a high number of genes misexpressed after vitamin D3 supplementation are common to both genotypes. On the other hand, when considering the biological pathways affected by these DEGs, the common pathways between $\mathrm{Wt}$ and $\mathrm{Tg}$ often include different subsets of genes for a given pathway or an inversed expression for the same gene. Our study underlines some well-known actions of vitamin D and related metabolites, namely its impact on immune and inflammatory processes and cell cycle, along with previously shown effects on nervous system molecules such as neurotrophins and nitric oxide. However, our results also comprise unexpected effects on the expression of hormonal transcripts and reveal regulation of genes involved in synaptic function, axon guidance, endothelial and vascular processes and stem cell pluripotency. A reassuring result is that among the 784 genes predicted to be related to vitamin $\mathrm{D}$ action in $\mathrm{Tg}$ animals, almost a third of them are indeed regulated after 5 months of supplementation. On top of that, the majority of the
A

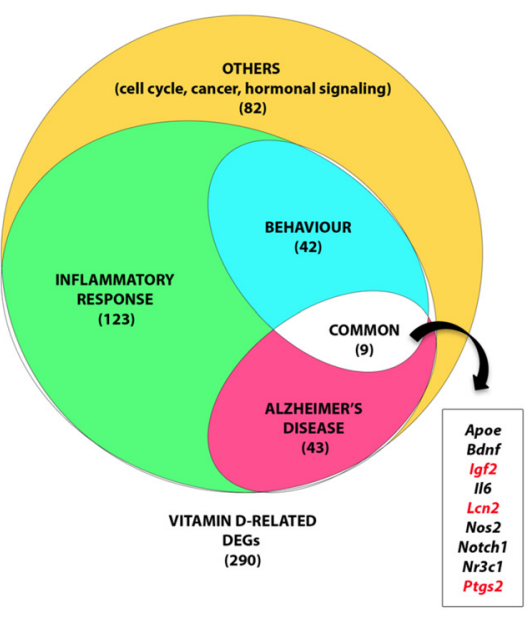

B

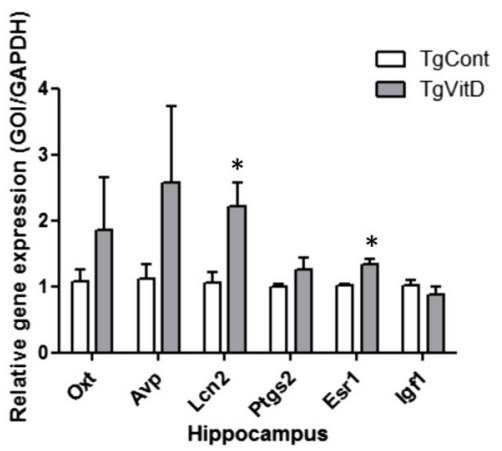

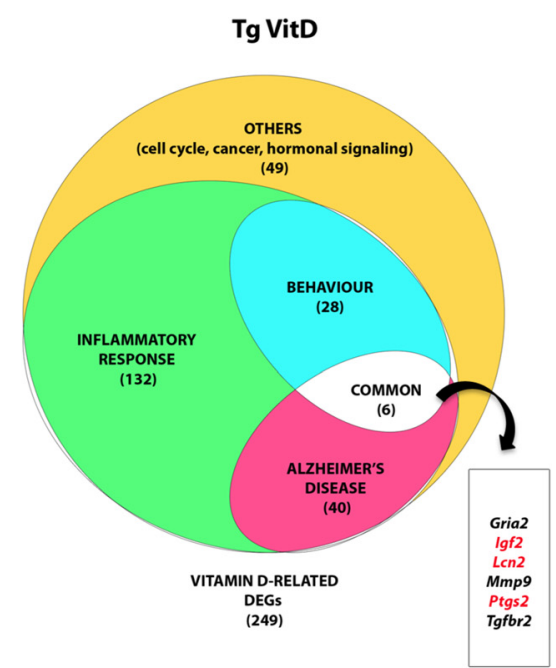

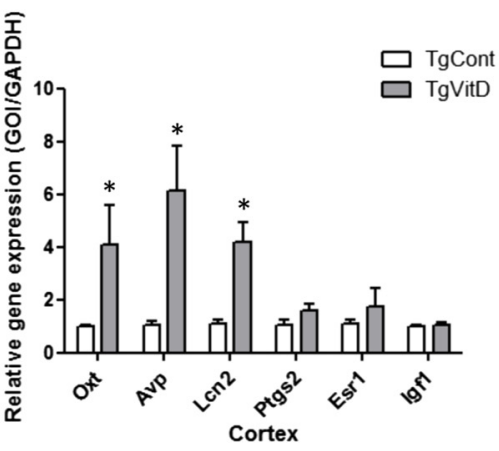

Fig. 3 Analysis of vitamin D3-related dysregulated genes indicates an association with inflammatory response, Alzheimer's disease and behavior. a Overall, 290 and 249 vitamin D-related DEGs are found misexpressed when comparing vitamin D3-supplemented wild type and transgenic mice with their unsupplemented littermates, respectively. Functional classification of these DEGs show importance of inflammatory, behavioural and Alzheimer's disease related processes. $\mathbf{b}$ qPCR validation of several dysregulated transcripts ( $n=6$ per group). An overexpression of the transcripts oxytocin (Oxt) and arginine vasopressin (Avp) is confirmed in the cortex as well as an upregulation of estrogen receptor 1 (Esr 1 ) in the hippocampus. The gene coding for lipocalin 2 ( $\operatorname{LCn} 2)$ is overexpressed in both the hippocampus and the cortex. ${ }^{*}=p<0.05$ 


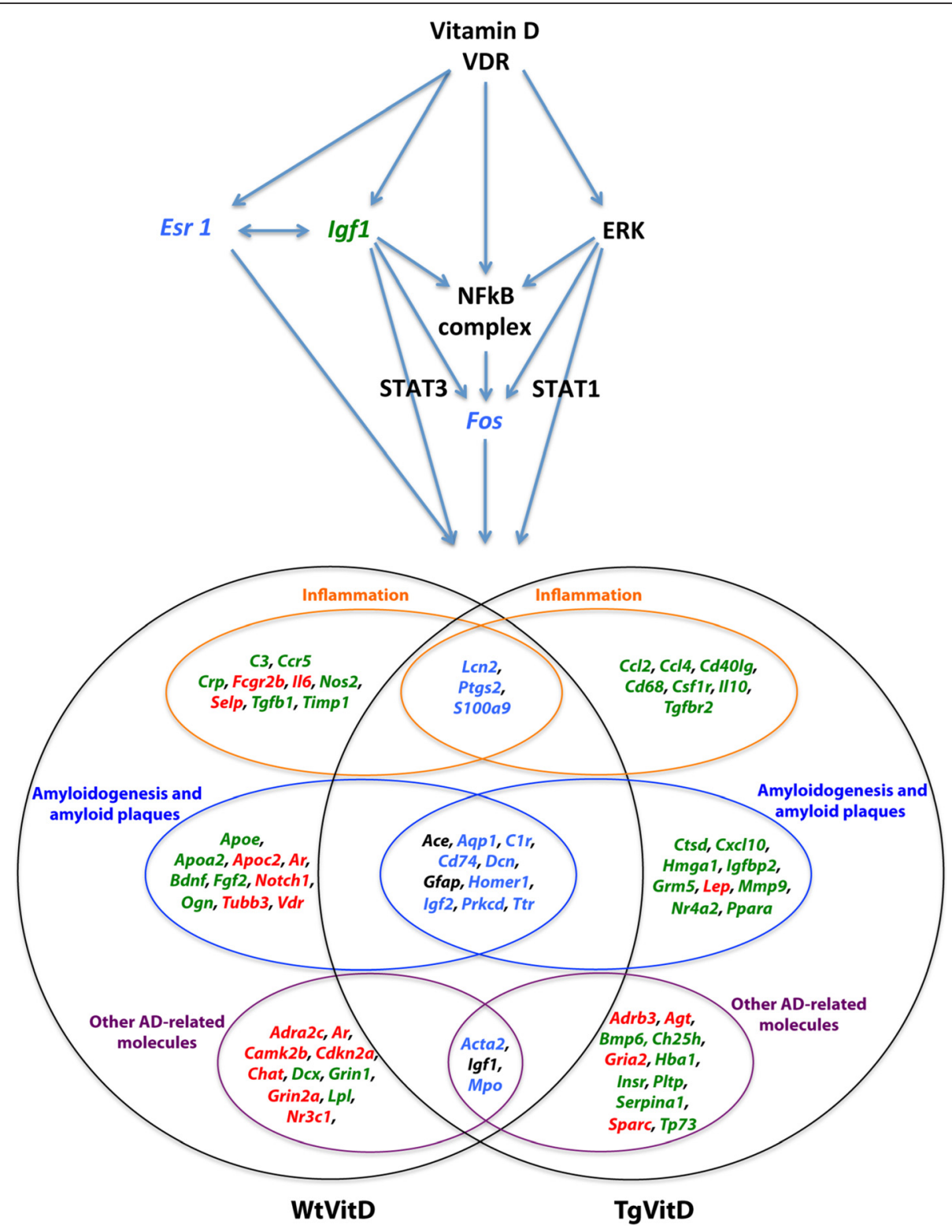

Fig. 4 Schematic view of the putative mechanisms of vitamin D3 action in the brain. Vitamin D3 or its related metabolites and their receptors act via four main regulators: IGF1, ESR1, ERK and NF-KB. Igf1 is underexpressed (green) in both strains while Esr1 is overexpressed in transgenic brains and underexpressed in wild type brains (blue). The expression of Erk and NF-KB is unchanged in both strains but many transcripts under their control are misexpressed in transgenic and wild type animals. Downstream gene regulators include Fos, Stat1 and Stat3. Fos is overexpressed in transgenic animals and underexpressed in wild type animals (b/ue). Overall, 72 vitamin D-related transcripts are associated to either inflammation (19 genes) or amyloidogenesis and amyloid plaques (29) or AD-related features (24). Sixteen genes are dysregulated in both strains (center areas). However, only three of them - Ace, lgfl and Gfap - are similarly misexpressed (black colour). Specific up- (red) and down-regulated (green) are indicated for each strain

vitamin D-related genes are associated to Alzheimer's disease, in both the Wt and Tg brains. We show that vitamin $\mathrm{D}$ action in the brain of this $\mathrm{AD}$ mouse model likely involves signaling through ESR1 and IGF1 and that a 5-month therapeutic intervention reduces the histological markers of the disease and restores learning and memory capacities.

\section{A common set of brain-associated genes regulated by vitamin D}

As mentioned earlier, no pangenomic study previously assessed the effect of vitamin D3 supplementation in a mouse model of Alzheimer's disease. As a result, no direct comparison can be performed. However, three teams performed a thorough transcriptomic analysis on 
i) brains from adult rats that were vitamin $\mathrm{D}$-deprived during gestation [27] ii) 1,25(OH)2D3-supplemented cultures of neurons and glia [28] or pericytes [29] and iii) hippocampus from middle aged rats after chronic treatment with increasing doses of vitamin D3 [30]. A cross examination of our data with those reported in these studies reveals that the dysregulated expression of 46 genes - Aaas, Aldoa, Atp2b4, Bcam, Bmp1, C3, Cat, Ccl2, Cntn4, Col16a1, Dpp6, Epas1, Fam120c, Fam70a, Fbln1, Fkbp1a, Foxc1, Gfap, Grp, Hspa12a, Htr2c, Igf1, Kdr, Kif1a, Lcat, Lpl, Ndst4, Nmbr, Nr4a2, Pde3b, Pmch, Polr1b, Ppp2r2b, Rab33b, Sdc4, Senp7, Serinc2, Slc17a6, Syt2, Thbd, Tia1, Trhr, Ttc39c, Vcam1, Vdr and Vps13cwas formerly observed. The newly generated list may appear relatively restricted when compared to our initial dataset of 3488 dysregulated genes. However, given the variety of scientific paradigms (depletion vs supplementation), the nature of the samples (cells vs different brain regions), the molecular diversity of the administered molecule (vitamin D3 vs 1,25(OH)2D3) and the heterogeneous size of the datasets, it is not of minor importance to be able to establish an inventory of commonly misexpressed genes in nervous cells or brain areas after vitamin D3 treatment. Moreover, some studies have performed targeted analysis of specific gene expression in nervous system cells or tissues. For instance, Kaneko and collaborators demonstrated that calcitriol regulates the expression of two human brain-related genes containing VDREs, tryptophan hydroxylase (Tph) and leptin (Lep) [31]. These genes are also modulated in the brains of either Wt or Tg mice in our study. In a set of experiments examining the effect of maternal vitamin D deficiency on fetal brain development, Hawes and colleagues found that the pups from deficient mothers display a modulated expression of Bdnf, Foxp2, Tgfb1 and Th, which are also affected in certain conditions of our study [32]. Altogether, these results underline the necessity for additional work to be performed on the genomic effects of vitamin D3 or 1,25(OH)2D3 in nervous system cells, as there are clearly multiple targets relevant to brain function and these could potentially explain a causal relationship between vitamin $\mathrm{D}$ status and brain aging or AD.

We chose to perform a literature-based analysis of possible VDRE-containing DEGs in our datasets. To avoid discrepancies between study designs, we initially based our search on a large in silico and microarray-based study by Wang and colleagues [6]. This revealed the presence of a very limited number of putative VDREs in our dataset. However, although ChiP-seq and genome-wide studies have found that the most frequent sequence located in VDR binding regions is the classic consensus VDRE motif, these data also suggest the presence of other motifs whose configuration diverge from the classic one and that might or might not interact directly with the VDR [33].
Moreover, there appears to be $1000-10,000$ possible chromatin VDR binding sites, according to the cell-type considered. In contrast the number of primary $1,25(\mathrm{OH}) 2 \mathrm{D} 3$ target genes is thought to be around 100-1000 per tissue, suggesting that some genes are controlled by more than one VDR binding site [33]. It is therefore difficult to conclude on the complete list of VDR direct targets in our dataset. For instance, the study by Latimer and coworkers, reported putative VDRE sequences in three genes from our dataset - Cntn4, Ppp2r2b and Syt2 - which were not previously identified by Wang and colleagues $[6,30]$. These potential VDRE-containing DEGs are involved in synaptic vesicle trafficking and neurotransmission, indicating a possible direct modulation of these processes by $1,25(\mathrm{OH}) 2 \mathrm{D} 3$ in the 5 XFAD animal model. Since the determination of true VDRE sequences would require further investigation and that vitamin $\mathrm{D}$ metabolites are also known to interact with various membrane-based signaling pathways, the search for indirect actions, for instance through modulation of immune processes, is not to be excluded.

\section{A confirmed immuno-modulatory role, several mechanisms of action}

The impact of vitamin D3 on inflammatory and immune processes is all but unexpected since it is now well established that vitamin $\mathrm{D}$ is a potent immune modulator [34]. $1,25(0 \mathrm{H}) 2 \mathrm{D} 3$ adjusts the expression of inflammatory cytokines and prevents the proliferation of proinflammatory cells [35]. As a general rule, 1,25(OH)2D3-treated T-cells produce less proinflammatory Th1 (IL-2, interferon- $\gamma$, tumor necrosis factor- $\alpha$ ), Th9 (IL-9) and Th22 (IL-22) cytokines and more anti-inflammatory Th2 (IL-3, IL-4, IL5, IL-10) cytokines [36-39]. In addition, Th17 activity is affected by vitamin D. Activated T-cells treated with $1,25(\mathrm{OH}) 2 \mathrm{D} 3$ secrete reduced levels of IL-17, interferon- $\gamma$ and IL-21 [40]. The overall picture remains slightly blurry. However, several key regulatory mechanisms begin to surface.

Characteristically, when calcitriol binds the VDR/RXR, the complex recognizes VDREs located in the promoter region of target genes and activates or inhibits their transcription. Concerning IL8 signaling, one of the top commonly affected processes in both Wt and Tg animals in our study, it is likely that IL8 is under the primary control of 1,25(OH)D and VDR as a study recently demonstrated the presence of VDR binding sites, in human monocytes, within the interleukin 8 (IL8) cluster [41]. However, direct activation/repression of gene expression is not the only mechanism by which the vitamin D system can act on immune processes [42]. As presented in Fig. 2, IL17A and IL17F signaling are affected by vitamin D3 supplementation in both strains. No known VDREs are present in the promoter regions of the TH17- 


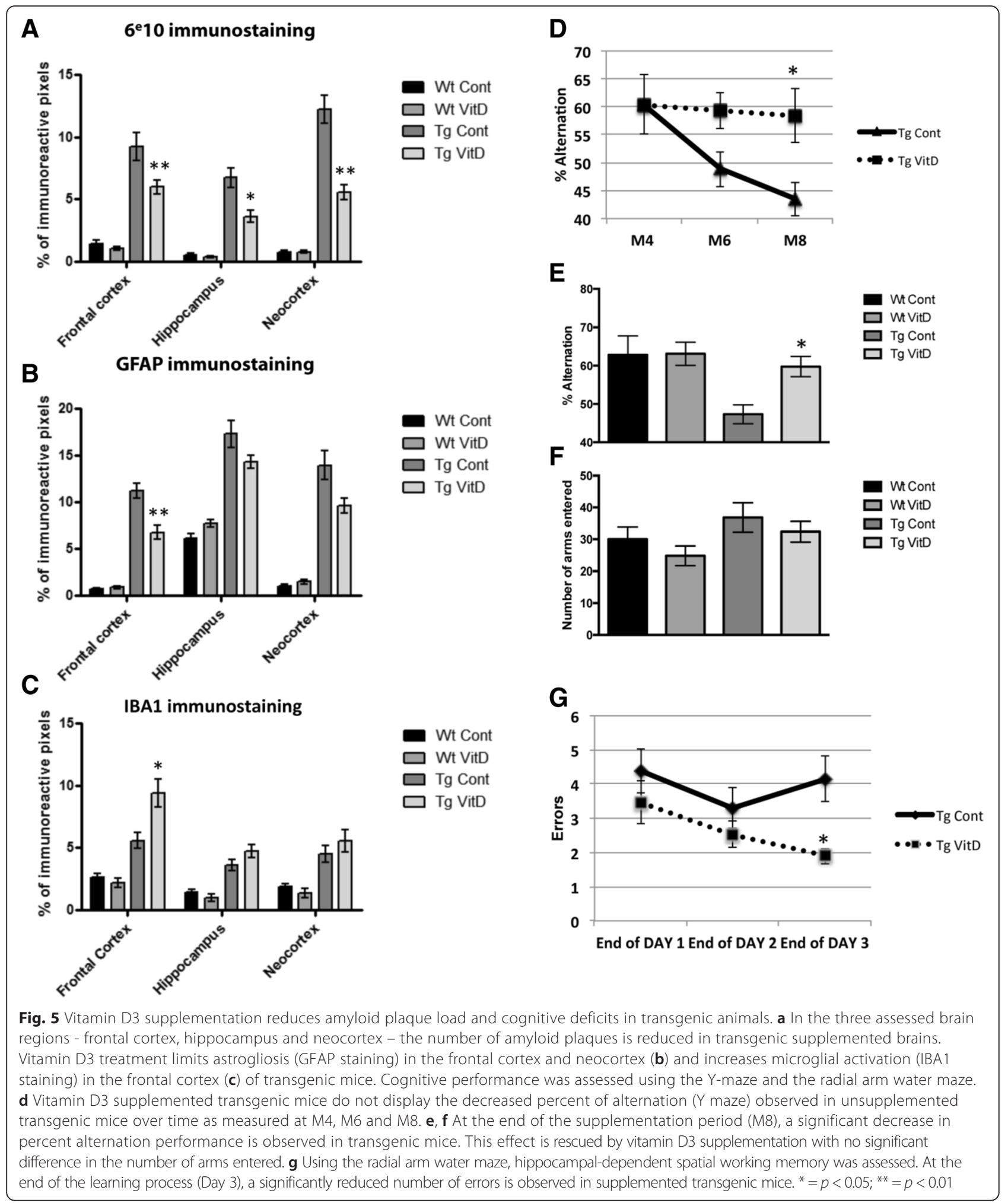

signature cytokines that are Il17a and Ill7f. Recently, it was reported that vitamin D inhibition of Th17 differentiation is obtained through modulation of Smads. More specifically, the presence of a negative VDRE in Smad7 promoter leading to $\operatorname{Smad} 7$ repression along with a VDR-dependent increase in Smad3 explain the changes observed in Th17 cells during differentiation. In parallel, $1,25(\mathrm{OH}) 2 \mathrm{D} 3$ indirectly regulates the expression of 
Th17-specific genes $I l 17 a$ and Il17f through activation of ERK [43]. On top of direct transcriptomic action and indirect signaling through vitamin D receptors, it is also possible that epigenetic mechanisms are also at play. For example, 1,25(OH)2D3 regulates TLR-mediated inflammation signaling by downregulating miR-155 in macrophages [44]. In our study, the modulated expression of several members of the TLR family (Tlr1, Tlr2 and Tlr7), with no known VDREs, could potentially involve such mechanisms [45].

In addition to these various mechanisms, $1,25(\mathrm{OH}) 2 \mathrm{D} 3$ interacts with other transcription factors, such as the glucocorticoid receptor, the nuclear factor of activated Tcells (NFAT) or NF-kB resulting in overall decreased inflammatory states [46]. It has been shown that, when activated by its ligand, the VDR dimerizes with the glucocorticoid receptor and together they bind to glucocorticoid responsive elements of genes, leading to an up-regulation of anti-inflammatory molecules and a down-regulation of pro-inflammatory genes [47]. Glucocorticoid receptor signaling is one of the top biological functions affected in our study, in both Wt and Tg brains. VDR is also able to bind to an NFAT binding site, inducing a diminished NFAT activity and downstream a repressed expression of IL2, cyclooxygenase 2 [48] and IL-17 [49]. Similarly, $1,25(\mathrm{OH}) 2 \mathrm{D} 3$ has been shown to inhibit NF- $\mathrm{kB}$ activation and signaling through up-regulation of $I \kappa B$ expression [50], interference with DNA binding [51] and by enhancing $\mathrm{FBW}-7$ dependent turnover of NF- $\mathrm{kB}$ subunits [52], leading to a reduced production of proinflammatory cytokines and pro-inflammatory enzymes such as cyclooxygenase 2 [53]. Deciphering the exact mode of action for 1,25(OH)2D3 modulation of immune and inflammatory pathways, whether it involves direct gene regulation, interactions and cross-talks between various signaling pathways, and epigenetic mechanisms is beyond the scope of this study. However, it is clear that in both the healthy and AD-like brain, vitamin D3 supplementation induces a strong effect on inflammatory and immune processes.

\section{A background-specific action of vitamin D3}

As established during the last 25 years, vitamin D and its metabolites play crucial roles in cell proliferation and differentiation, neuroprotection, neurotransmission and neuroplasticity [54]. However, as observed in the immune system, vitamin D3 action is space- and timespecific. For example, a hypervitaminosis D alters the synthesis of calcium binding proteins in the caudate/ putamen but not in the hippocampus and the cerebral cortex [55]. Likewise, 3 weeks after the induction of an experimental allergic encephalomyelitis, vitamin D3 supplementation provokes a massive downregulation of inducible nitric oxide synthase (iNOS) only in the rat cerebellum and brainstem [56]. The time window for vitamin $\mathrm{D}$ depletion or supplementation can be essential as well. A transient developmental vitamin D deficiency induces persistent morphological and molecular changes in the adult rat brain [57-59] while an adult vitamin $\mathrm{D}$ deficiency is associated with less profound modifications [60].

An important finding from our transcriptomic analysis is the effect of the pathological context on gene response to vitamin D3 treatment. Indeed, our study provides evidence that vitamin D3 has distinct genomic effects in a non-pathologic and an AD-like brain. It is clear that, when given to healthy animals, vitamin D3 induces dysregulation of genes implicated in an important number of nervous system related pathways, whereas it appears to act preferentially on immune system processes in $\mathrm{Tg}$ mice, as illustrated in Fig. 2 and Additional file 4. When considering nervous system related pathways, distinct actions also appear. For instance, the non-pathologic brain expresses genes associated to neurological functions such as neurotrophins or tight junction modulation while the pathologic brain activates/represses genes related to catecholamine synthesis or nitric oxide signaling (Fig. 2). Another mean to demonstrate the effect of the pathological background on gene dysregulation is to observe the subtle strain-associated changes in a common canonical pathway. One of the most remarkable is the $W n t / \beta$-catenin signaling. Out of seven genes whose expression is dysregulated in both strains - Dsh, Frizzled, Lef/Tgf, Lrp1, Rar, Tgfbr, Wht - 5 are inversely misexpressed, indicating a putative opposite action of vitamin D3. In addition, 12 and 7 genes are exclusively dysregulated in the wild type and transgenic brains, respectively (Additional file 6).

Several studies have highlighted the importance of various factors, such as genetic settings, pathological backgrounds, organ areas, cell subtypes, delivery time windows, molecule concentrations, in determining the response to vitamin D treatment. We can list a few examples. Conversely to cells from healthy individuals, $1,25(\mathrm{OH}) 2 \mathrm{D} 3$ increases the production of IL-2 in peripheral blood mononuclear cells from hemodialysis patients [61]. 1,25(OH)2D3 addition in the culture medium of either monocytes or macrophages induces an up-regulation and a down-regulation of IL-1 and IL- 6 mRNA, respectively. These results were abolished or modified when cells, before being stimulated with LPS or TNF- $\alpha$, were preincubated with 1,25(OH)2D3 [62]. 1,25(OH)2D3 triggers a lessened expression of IL-10, followed by an increased production, at a later stage [46].

Such regulation variability may explain some observed discrepancies between the mouse strains used in the current study. Genetically similar mice from the same ages were fed with the same diet, during the same time 
window, and the same brain areas were analyzed. Yet, one strain differs from the other by carrying two mutated human genes - APP and PSEN1 - that induce molecular, morphological and behavioral changes. The 5XFAD mouse model is an inflammatory model $[4,63]$ and, as mentioned above, 1,25(OH)2D3 induces a different response when acting on an inflamed tissue. Interestingly, this may even apply to the canonical pathways that are dysregulated in both strains (Additional file 4). In most if not all cases, the two lists of misexpressed genes are not fully identical. This confirms that the pleiotropic action of vitamin D3 and its related metabolites strongly varies according to the health status of the animal.

In addition, the strain-associated differences may be related to the mechanism of action of vitamin D metabolites at play, whether it is a genomic response or the induction of membrane based signaling pathways. In a recent review, Michael Berridge develops the hypothesis that vitamin D acts as a guardian of phenotypic stability in a cell- and context-specific manner [64]. This stability is maintained through modulation of various intracellular signaling pathways that are linked to vitamin D action. For instance, vitamin $\mathrm{D}$ is capable of regulating the expression of many components of pathways activated by insulin, TGFB1, WNT and NOTCH [65], whose mRNA expression is affected in our study.

\section{A strong link with Alzheimer's disease in both Wt and Tg} The 5XFAD model is based on the insertion of two human transgenes leading to a major increase of $A \beta 1$ 142 that accumulates rapidly in the brains of transgenic animals. Overall, this model is both an inflammatory and amyloidogenic model of Alzheimer's disease [2, 4, 66]. As seen so far, the inflammatory component present in Tg animals is highly addressed by vitamin D3 treatment and, to a lesser extent, in Wt animals. Other effects of gene dysregulation in the brain of both Wt and $\mathrm{Tg}$ mice relate to Alzheimer's disease. For instance, one of the commonly dysregulated pathways, described in Additional file 4, concerns the neuroprotective role of THOP1. THOP1, an oligopeptidase whose levels increase upon $\mathrm{A} \beta$ exposure, is found overexpressed in human $\mathrm{AD}$ brains, and appears to engage in neuroprotective activities against toxic effects of $A \beta$ at early stages of the disease [67]. This pathway is significantly affected in our study, however it is difficult to conclude about the outcome induced by such dysregulation at the functional level, especially since the expression of different genes in the pathway is modified according to the genotype.

Within the THOP1 pathway, the expression of angiotensin-converting enzyme (ACE), which converts angiotensin I to angiotensin II, a potent vasoconstrictor, is affected in both wild type and transgenic animals. No study has focused on the effect of vitamin D3 supplementation on ACE expression. However, it has been observed that VDR knockout mice display an increased production of ACE mRNA [68]. Interestingly, this metalloprotease is involved in Alzheimer's disease since human $A C E$ increases degradation and cleavage of $A \beta$ [69-72].

Another interesting result is the finding that a number of DEGs relate to vascular processes. Angiogenesis is a complex process that involves the activation and modification of several signaling pathways within endothelial cells. A key mediator of this process is VEGF. Pathological angiogenesis is now considered as a key contributor to the development of AD. Substantial evidence suggests that the neurodegenerative process can be caused by cerebral hypoperfusion which induces reduced oxygen, glucose and nutrient supply to the brain, and damages the parenchymal cells and the blood-brain barrier (BBB). BBB dysfunction promotes oxidative stress, inflammation, paracellular permeability and dysregulation of nitric oxide [73]. Several signaling pathways such as VEGF signaling, tight junction signaling, nitric oxide signaling in macrophages and eNos signaling are disturbed by vitamin D3 treatment, especially in Tg mice.

Conversely, we observed a misexpression of Apoe mRNA only in wild type supplemented animals. This protein is associated to cardiovascular diseases as well as Alzheimer's disease [74]. No direct interaction between vitamin D3 and ApoE has been unveiled so far. However, several studies indicate putative interplays. For example, the VDR mRNA regulates the phosphorylation and production of STAT1 [75] which in turn is involved in the expression of apoE mRNA [76]. Furthermore, the vitamin D system interacts with IGF1 and Esr1 (see below), the latter upregulating Apoe mRNA in rat primary culture of hippocampal neurons [77]. On the other hand, ApoE $\varepsilon 4$ alleles have been associated with reduced memory function and higher serum $25(\mathrm{OH}) \mathrm{D}$ concentrations [78].

Overall, the fact that a large number of vitamin Drelated genes are categorized as AD-related in both Wt and $\mathrm{Tg}$ animals is intriguing. This is suggestive of a close link between vitamin D signaling and AD-related signaling, as has been proposed by researchers $[25,79]$. Although we observed a positive effect of vitamin D3 treatment on the amount of amyloid plaques, we never detected a misexpression of the endogenous App transcript in our transgenic or wild type animals. This comes as a relative surprise since it has been reported that either the cotransfection of VDR or a calcitriol treatment reduces, in a dose dependent manner, APP transcription in neuroblastoma cells [18]. It is hypothesized that VDR interacts with SMAD3 [80], a transcription factor known to regulate APP transcription through TGF beta signaling [81]. However, our data failed to confirm these findings. In wild type mice, 
vitamin D3 supplementation induces an under-expression of Smad6, Tgfb1 and Tgfbr1 transcripts without affecting App expression. In addition, no misexpression of these four mRNAs is observed in transgenic animals. It is therefore likely that other intermediate molecules, such as those described below, are involved in the reduction of amyloid burden.

\section{An unexpected regulation of oxytocin and arginine vasopressin transcripts in the cortex}

One very intriguing result is the mRNA regulation of a number of hormones classically known to be present in the pituitary axis. It is true that OXT and AVP, for instance, act as both hormones and central neurotransmitters. However, to our knowledge, the presence of local regulation of gene expression in the hippocampus or cortex for both these hormones has never been reported before. Binding sites for both hormones have been described in different central regions such as the amygdala, septum and olfactory region [82]. However, while AVP receptors have been reported within the hippocampus no OXT receptor has been found in this area [83]. Both neuropeptides regulate rodent, primate and human social behaviors and stress responses [84]. AVP influences memory processes in the brain by facilitating memory consolidation and retrieval $[85,86]$. Regarding its role in $\mathrm{AD}$ pathology, a significant decrease in AVP concentration was found in the brain of AD patients while application of AVP improves learning and memory in aged people and in rats having received $A \beta$ [87-90]. OXT regulates hippocampal synaptic plasticity and improves hippocampal-dependent cognitive functions [91-93]. The direct or indirect regulation of these neuropeptides by vitamin D3 could have important implications for a number of behavioral and cognitive processes in both the normal and pathological brain. Differential expression of these two genes (Oxt and $A v p)$ was then measured by qPCR. A significant increase for both these genes was only confirmed in the cortex, although the same tendency is observed in the hippocampus. It appears that important inter-individual variations are present among the tested mice, further supporting the idea that vitamin D3 acts not only in a space- and time-specific manner, but also in an individual-specific way.

\section{A putative role of insulin growth factor 1 and estrogen receptor 1 as downstream regulators}

Four other gene expressions were assessed with $\mathrm{qPCR}$ and, once again, not all were validated in each brain area analyzed. Lcn 2 and Ptgs 2 are both involved in inflammatory signaling processes and have been found to contribute to amyloid response in AD [94, 95]. Esr1 and Igf1 induce signaling pathways known to be affected in AD. Several interactions between the estrogen and vitamin $\mathrm{D}$ endocrine system have been described so far. $1,25(\mathrm{OH}) 2 \mathrm{D} 3$ may play an important role in estrogen biosynthesis suggested by the fact that serum estrogen levels are decreased in VDR knock-out mice as compared with wild-type mice [96]. The direct action of vitamin $\mathrm{D}$ on estrogen signaling is also cellspecific as demonstrated by the fact that $1,25-(\mathrm{OH}) 2 \mathrm{D} 3$ increases estrogen receptor (ER) expression in osteoblastlike cells, while it exerts a negative effect on ER in MCF-7 human breast cancer cells $[97,98]$. An alteration in ER distribution in $\mathrm{AD}$ hippocampal neurons has been described, and, more precisely, a shift in cellular localization of these receptors inhibits the development of AD pathology [99, 100]. Collectively, investigations suggest that levels of estrogen receptors play an important role in neuroprotection and against neuroinflammation-induced degeneration in $\mathrm{AD}[101,102]$. ESR1 has also been shown to interact directly with amyloid processing through nongenomic signaling via activation of MAPK/ERK pathway [103]. Recently, two potential negative VDREs have been identified in the promoter region of Esr1 [104] suggesting a direct transcriptional action of vitamin D/VDR on ER leading to an altered estrogen signaling mechanism important to both Wt and AD-like brains. A possible mechanism by which ESR1 confers neuroprotective effects in $\mathrm{AD}$ is through interaction with IGF1R. Both in vivo and in vitro studies have revealed interaction between ERs and IGF1R in the promotion of neuronal survival, synaptic plasticity and against $A \beta$ toxicity $[105,106]$. Insulin signaling is emerging as an important event in neurodegenerative processes and aging in general. However, inconsistencies regarding the role of insulin-like signaling and its association to AD have appeared. In rodents, reduced insulin/IGF1 signaling slows aging and therefore prevents development of neurodegenerative diseases [107] but normal aging is associated with declining levels of IGF1 and administration of insulin can improve cognitive function in AD patients [108, 109]. Regardless, in vivo evidence shows that AD-like pathology is significantly delayed in IGF1R knock out mouse models of AD [110, 111]. Potential crosstalks between vitamin D and IGF1 signaling have been put forward. VDR knock-out mice display decreased expression of Igf1, Igflr and $N f-k b$ [112]. 1,25(OH)2D3 also regulates the expression of a well-known antiaging gene, Klotho $(K l)$, whose expression is modified in the hippocampus of both $\mathrm{Wt}$ and $\mathrm{Tg}$ mice in our study. $K l$ dysregulation is linked to modulation of Insulin/IGF1 signaling pathways [113]. Taken together, these results largely support both direct and indirect action of vitamin D/VDR on ESR1 and IGF1 signaling pathways in both Wt and 5XFAD mice, as a mechanism to reduce brain aging processes. 


\section{Convergent data on amyloid plaque load and divergent results on astrogliosis}

The bulk of our study focuses on describing the similarities or differences induced by chronic vitamin D3 supplementation at the transcriptomic level in Wt and $\mathrm{Tg}$ animals at M9. Importantly, the altered gene expression translates into a modification of functional outcomes. We note a link between the action of vitamin D3 on gene regulation in our model and its effect at the histological and behavioral levels. We show here that 5 months of vitamin D3 treatment restores learning and memory performance in $\mathrm{Tg}$ animals in both the Y-maze and RAWM but does not affect cognitive outcome in Wt mice. This is accompanied by a decrease in the number of amyloid plaques, astrocytic reactivity and subtle changes in microglial activation for $\mathrm{Tg}$ animals having been fed a vitamin D3 diet. Several studies have shown an improvement in memory and cognitive function in different models of $\mathrm{AD}$ or aging following vitamin $\mathrm{D} 2$, vitamin D3 or $1,25(\mathrm{OH}) 2 \mathrm{D} 3$ treatment. In their work, $\mathrm{Yu}$ and colleagues used young A $\beta \mathrm{PP}$ transgenic mice and found an amelioration of performance in the Morris Water Maze (MWM) for animals under a high vitamin D3 diet. These behavioral changes were accompanied by a diminished $A \beta$ load, along with an increase in astrocytic reactivity, NGF levels and decreased TNF- $\alpha$ in the brain of treated mice. This study focused on a preventive action of vitamin D3, which might explain some of the differences observed when comparing their data to ours. Specifically, the increase in astrocytic marker GFAP is inconsistent with the diminished GFAP staining observed in our study [26]. This discrepancy might reflect the balance by which vitamin D3 exerts its effects according to the pathological context and the time of delivery. An increase in GFAP expression is a hallmark of reactive gliosis and is found in many neuropathological conditions, including AD. The functional changes associated to this increased expression however are not fully understood. To study the functional outcomes of GFAP dysregulation on the surrounding brain tissue and cells, GFAP knock-outs (KO) have been generated and when combined to brain injury models, studies suggest that GFAP increase is associated to protective mechanisms $[114,115]$. When GFAP KO mice were crossed with a mouse model for $\mathrm{AD}$, the deposition of amyloid plaques was accelerated. Furthermore, neuritic dystrophy was exacerbated and the interaction of astrocytes with plaques was decreased [116]. These observations lead to the conclusion that astrogliosis can be considered as a brain defense mechanism attempting to prevent plaque formation and neuronal damage, and this would take place during the onset of the disease. However, we cannot rule out that, at the same time, gliosis affects the synaptic and metabolic support functions of astrocytes [116, 117].
It is then probable that with age and repeated insults, chronic astrocyte reactivity may become deleterious, engaging the opposite effect of vitamin D3 on GFAP expression when compared to a younger tissue. We and others have shown that genes involved in glial reactivity and inflammation are among the earliest affected during disease pathogenesis in the 5xFAD model and that these are correlated with cognitive impairment [4]. We show here that vitamin D3 is able to act specifically on both astrocytic and microglial activation at both the transcriptomic and histological levels. In the AD brain, microglial activation is the driving force for the elaboration of an inflammatory cascade [118] and reports show an upregulation of VDR mRNA in microglia stimulated by $A \beta$ in vitro [119], indicating that microglia found around amyloid plaques could increase their responsiveness to vitamin $\mathrm{D}$ metabolites. Microglia, unlike the other cells of the nervous system, stems from the myeloid lineage and is considered the macrophages of the brain. As discussed thoroughly here and elsewhere, the vitamin D system displays potent antiinflammatory roles in immune cells and the increase in microglial activity in the frontal cortex of 5xFAD mice reflects the capacity of vitamin D3 to balance the pro- and anti-inflammatory cytokine production regulated by microglia $[118,120]$. In addition, this enhanced activation of microglia at the proteomic level could also reflect increased phagocytic activity of $A \beta$, a process demonstrated to be promoted by vitamin $\mathrm{D} 3$ in the macrophages of $\mathrm{AD}$ patients $[121,122]$. Once again, it appears that vitamin D3 acts on both nervous system and the immune system pathways to reduce alteration in neuronal metabolism and further preserve cognitive outcomes.

\section{An age- and concentration-dependent action on cognition}

The study by $\mathrm{Yu}$ and colleagues does not present the effect of vitamin D3 on cognitive functions in the Wt counterpart, leaving no comparison possible [26]. Accordingly, an 8 week treatment with intraperitoneal injections of $1,25(\mathrm{OH}) 2 \mathrm{D} 3$ in a different mouse model of AD restored learning and memory deficits, assessed by the fear conditioning paradigm, compared to vehicle-treated $\mathrm{Tg}$ mice but did not affect cognitive performance in non-Tg animals [123]. Yet, another study, which tested a 7 months vitamin $\mathrm{D} 2$ supplementation in another $\mathrm{AD}$ mouse model, concluded that, in this case, vitamin D2 improved cognitive performance more reliably in Wt mice rather than $\mathrm{Tg}$ at M9 [124]. And when focusing solely on the implication of vitamin D in normal aging and memory disabilities, Latimer and colleagues showed that a high vitamin D3 diet $(10,000 \mathrm{IU} / \mathrm{Kg}$ diet) lasting 5 to 6 months prevented cognitive decline in aging rats. The study demonstrates a causal relationship between enhanced learning and memory during aging with vitamin D3 status which is 
underlined by enhanced synaptic transmission due to gene expression changes in the brain [30]. At approximately the same time, Briones and Darwish performed subcutaneous injections of $1,25(\mathrm{OH}) 2 \mathrm{D} 3$, for 21 days, to both young and aged rats (6 and 20 months, respectively) and observed an attenuation of cognitive impairment accompanied by enhanced brain energy metabolism, modulation of inflammatory and redox state in aged rats after treatment compared to controls [125, 126]. Both these studies underlie a role for vitamin D metabolite supplementation in the preservation of cognitive function in "normal" aging animals. The middle-age period is characterized by the onset of subtle changes in cognitive performance that might not be detected by the straightforward tests that are the Y-maze and RAWM. It is probable that M9 is not old enough to detect memory decline in Wt animals or that tests aiming at detecting more subtle performance changes in executive function or processing speed would be required to allow analysis of vitamin D3 treatment on cognitive performance in Wt aging animals.

\section{Conclusions}

Classically, investigations into physiological processes and neurodegenerative disease pathogenesis have moved from the whole organism to the molecular level as the advent of genome-wide microarrays and large-scale genome sequencing have become powerful tools for probing physiological mechanisms. Vitamin D signaling is ideally suited for genomic analysis as its main receptor VDR is a direct regulator of gene transcription. However, although transcriptomic technologies have evolved greatly, there is still no consensus about an optimal way to analyze transcriptomic data. This renders comparison with other studies rather difficult, especially when platform and data analysis programs differ. The growing knowledge about epigenetic mechanisms at play in gene regulation and its relevance to vitamin $\mathrm{D}$ action in the brain could not be addressed in this study but needs further investigation in future experimental designs. The absence of a clear consensus motif for VDREs also impedes the pinpointing of direct vitamin $\mathrm{D}$ targets. Moreover, a 5-month supplementation entails that transcriptional activation is not the only mechanism at play, and that membrane-based actions of vitamin D and its related metabolites are to be considered. The interactions between the vitamin D system and other signaling pathways are clearly as important as direct transcriptional activation or repression of 1,25(OH)2D3 targets, as shown in this study.

The aim of this study was to i) assess the potential therapeutic benefit and the mechanisms of action of a chronic vitamin D3 supplementation in an AD model and ii) extract information about specific signaling pathways affected by vitamin D3 in the nervous system. Therefore, validating each DEG obtained by microarray assay using $\mathrm{qPCR}$ or proteomic approaches was largely beyond the scope of the study but this needs to be further addressed, especially for those genes put forward as key partners or downstream actors. It is important to note that the discordant results observed between microarray data and qPCR analysis might reflect the importance of inter-individual variability in response to vitamin D3 treatment but also the limitations for each method used. Indeed, transcriptomic data are normalized to global measures while qPCR results are obtained in reference to one housekeeping gene. Concerning IgfI mRNA quantification, it is also likely that putatively low levels followed by further reduction in gene expression is more error prone and reaches the limit of qPCR analysis. Moreover, as our study emphasizes the time-, background- and individual-specific action of vitamin D3 in the brain, it is obvious that differential activity at the transcriptomic level is operated between the cortex and hippocampus. Additional analysis of our data would allow for more precise deciphering of vitamin D3 impact in each brain area known to be affected in AD. The study was also designed using a female cohort, and it would seem extremely relevant to repeat such experiments in male animals. This could help contribute to the ongoing debate about the relevance of gender differences in the pathogenesis of the disease. Especially since estrogen signaling appears to play an important part in the events observed here, along with the mRNA dysregulation of a certain number of hormones, we cannot exclude a sex-impact to be considered in the way vitamin D3 acts on brain cells.

Lastly, animal studies using vitamin D treatment in $\mathrm{AD}$ models, including ours, show improvement in various markers of the disease but interventional clinical trials, to date, failed to show such effects. It is important to bear in mind that animal models of AD do not recapitulate fully the complex physiopathology of the disease and major differences in regulation by the vitamin D signaling system are observed, according to the species concerned [127], possibly further increasing the gap between the results obtained from animal and human studies. Moreover, we chose to place ourselves in a therapeutic context, however, reproducing such a study in a preventive manner would allow refining the analysis of vitamin D3 action in a time-dependent manner. Indeed, one major current problem concerning clinical trials, using vitamin $\mathrm{D}$ as a protective agent against cognitive decline and $\mathrm{AD}$, is the time and dose for treatment. When comparing our study to others, we highlight the differences in functional outcomes depending on the time of treatment, the dose or metabolite used. As with clinical trials, there is a great need for additional 
work in rodents before deciphering the exact mechanisms of action of vitamin $\mathrm{D}$ in the nervous system. However, we feel confident that the present dataset is a useful public resource which reflects the variety and pleiotropy of vitamin D3 actions in the brain with particular emphasis on the crosstalk between vitamin D3 activated pathways and those affected in $\mathrm{AD}$ and should allow future studies to further validate the use of vitamin D3 as a potent therapeutic agent in AD.

\section{Methods}

\section{Animals and experimental design}

Female 5XFAD transgenic mice were used for this study. These mice overexpress two transgenes bearing five mutations linked to familial AD: human APP (Swedish mutation K670N, M671L; Florida mutation I716V; London mutation V717I) and human presenilin 1 (PSEN1 M146L, L286V), under transcriptional control of the mouse Thy1 promoter. 5XFAD lines from the B6/SJL genetic background were maintained by crossing hemizygous transgenic mice with B6/SJL F1 breeders. These mice exhibit AD-related symptoms earlier than other animal models and amyloid deposition starts in the cortex and subiculum at 2 months of age $[2,128]$. Heterozygous 5XFAD transgenic animals and wild type (Wt) controls were obtained after breeding of progenitors purchased from the Jackson Laboratory. Newborn pups were genotyped by polymerase chain reaction (PCR) of tail DNA biopsies in order to detect the human PSEN1 gene as previously described [128]. Animals were weaned at 4 weeks of age and fed an identical diet until M4. Mice were then allocated to different groups: Wt animals on a control diet (1000 IU/kg) $(n=10)$, Wt animals on a vitamin D3 enriched diet $(7500 \mathrm{IU} / \mathrm{kg})(n=11)$, transgenic animals on a control diet $(n=14)$ and transgenic animals fed with the vitamin D3 enriched diet ( $n=16)$ (INRA, France). Mice were tested at M4, M6 and M8 in the Y-maze, and at M8 in the 6-radialarm water maze before euthanasia at M9. Animal experiments were approved by the Ethics Committee of the Medical Faculty of Marseille and were carried out in accordance with the guidelines published in the European Communities Council Directive of November 24, 1986 (86/609/EEC). All efforts were made to reduce animal suffering and the number of mice needed for the study.

\section{Behavioural testing \\ Y-maze}

Spontaneous alternation in the Y-maze was tested according to the following protocol: each mouse was placed in a random arm of the symmetrical Y-maze and was allowed to explore freely through the maze during an 8 min session. The sequence and total number of arms entered was recorded. Arm entry was considered complete when the hind paws were completely in the arm. Experiments were done blind with respect to the genotype and diet of the mice. Washing with water and ethanol was performed between each passage. Percentage of alternation was determined as follows: number of triads containing entries into all three arms/maximum possible alternations (total number of arms entered - 2) x 100.

\section{6-Radial arm water maze}

The 6-RAWM is a hybrid of the Morris water maze and a radial arm maze. The test allows assessment of spatial and reference memory. The mouse version of this maze uses a circular pool with six swim alleys (arms) radiating out from an open central area with a hidden escape platform submerged at the end of one goal arm. The overall design of the study was adapted from Alamed and collaborators [129], using a 3-day protocol containing 12 sessions per day. Visual cues were displayed around the room and the experimenter remained visible throughout the training sessions. For this procedure the goal arm differed between mice but was held constant for each mouse during all trials with a different start arm on successive trials. The first day of training comprised of alternating between hidden and visible platform. During the 12 trials of the second and third day, the platform remained hidden and the mice were required to use the visual cues to locate the goal arm. When a mouse entered a wrong arm, which did not contain the platform, an error was scored. At the end of the procedure, mice were tested in the circular pool using a visible platform, to ensure their visual abilities were satisfactory for inclusion in the study.

\section{Tissue isolation}

Brain tissues were collected at M9, from all groups. Mice were anesthetized with isoflurane before sacrifice and brains isolated from each animal. The hippocampus and neocortex from a half brain were dissected, snap-frozen in liquid nitrogen and stored at $-80{ }^{\circ} \mathrm{C}$ until use. The other hemi-brain was placed in $4 \%$ paraformaldehyde during 6 days at $4{ }^{\circ} \mathrm{C}$, for further immunohistological processing.

\section{Tissue processing and immunostaining}

Coronal brain sections from hemi-brains previously collected and fixed in $4 \%$ paraformaldehyde were serially generated using a cryostat and stored at $-20{ }^{\circ} \mathrm{C}$ in six-well plates containing a cryoprotectant (30 \% glycerol; $30 \%$ ethylene glycol (Sigma Aldrich, Saint-Quentin Fallavier, France) diluted in 0,05 M PBS phosphate buffered saline $(\mathrm{pH}$ 7.4) until being processed for immunostaining.

After washing in PBS, floating sections were incubated, during $1 \mathrm{~h}$ at room temperature (RT), with a blocking buffer (3 \% BSA, $0.1 \%$ Triton X-100 in PBS pH 7.4) and, overnight at $4{ }^{\circ} \mathrm{C}$, with the following primary 
antibodies diluted in the blocking solution: rabbit polyclonal anti-GFAP (1/500, Dako France, Trappes, France), mouse monoclonal anti-A $\beta$, 6E10 (1/300, Covance, Eurogentec, Angers, France) and rabbit polyclonal antiIBA1 (1/200, Wako, Sobioda, Montbonnot-Saint-Martin, France). Then, slices were rinsed in PBS and incubated for $90 \mathrm{~min}$ at RT with cross-absorbed Alexafluor 488conjugated anti-rabbit or 594-conjugated anti-mouse secondary antibodies (1/500, Life Technologies, Saint Aubin, France) along with Hoechst blue (1/1000, Sigma Aldrich) in dark conditions. After several washes in PBS, slides were mounted with ProLong Gold Antifade reagent (Life Technologies).

\section{Microscopic analysis and quantification of gliosis and amyloid plaques}

Quantification of gliosis and amyloid plaques were performed on $30 \mu \mathrm{m}$ thick brain coronal sections costained with either GFAP and 6E10 or IBA1 and 6E10 antibodies, at the frontal cortex, hippocampal and sensory cortex levels. Images were acquired using an inverted Axio Observer microscope (Zeiss, Jena, Germany) equipped with DAPI, FITC and TRITC epifluorescence filters. Images of large brain sections were obtained using the mosaic mode of the Axiovision software (Zeiss). For 6E10, GFAP and IBA1 staining quantifications, ImageJ software was used. The pictures were binarized to 16 bit black and white images and a fixed intensity threshold was applied for all images. Percentage of covered area by the fluorescent staining was calculated. Eight mice per group and three sections per mouse at three different levels were used.

\section{RNA isolation}

Total RNA was isolated from the snap-frozen hippocampi and cortices using RNeasy Mini kit (Qiagen, Courtaboeuf, France), according to the manufacturer's instructions. RNA concentration was determined using a Nanodrop 2000 spectrophotometer (Life Technologies ThermoFisher Scientific, Villebon sur Yvette, France) and RNA integrity assessed on an Agilent 2100 Bioanalyzer (Agilent Technologies, Les Ulis, France).

\section{Microarray assay}

RNA samples from three animals in each group were pooled for microarray hybridization. Sample amplification, labeling, and hybridization were performed in line with the Agilent one-color microarray-base analysis (low input quick amp labeling) protocol (Agilent Technologies). Briefly, total RNA was reverse-transcribed into cDNA using the $\mathrm{T} 7$ promoter primer. The reaction intending to synthesize cyanine-3-labeled cRNA from cDNA was performed in a solution containing dNTP mix, T7 RNA polymerase and cyanine 3-dCTP and then incubated at $40{ }^{\circ} \mathrm{C}$ for $2 \mathrm{~h}$. Labeled cRNA was purified and fragmented before hybridization on Agilent 8x60k Mouse Gene Expression Arrays (Agilent Technologies), containing 62,975 oligonucleotide probes, at $65{ }^{\circ} \mathrm{C}$ for $17 \mathrm{~h}$. Raw microarray signals were scanned and extracted using Agilent Feature Extraction Software (Agilent Technologies). AgiND $\mathrm{R}$ package was used for quality control and normalization. Quantile methods and a background correction were applied for data normalization. Microarray data are available in the ArrayExpress database under accession number EMTAB-1937.

\section{Microarray data analysis}

Biological interpretation of the data was performed using two different programs. The NIH DAVID tool was used to obtain functional annotation clusters related to the datasets of interest. Ingenuity Pathway Analysis (IPA, Ingenuity Systems) was also used to identify biological functions and upstream regulators relevant to the lists of DEGs analyzed. The main criterion to validate a differentially expressed gene was a fold change over 1.5 or under -1.5 when considering expression values in the group supplemented with vitamin D3 relative to the control diet group, whether considering wild type or transgenic animals. Upregulated and downregulated genes were analyzed in the same datasets to obtain the biologically relevant function categories. Right-tailed Fisher's exact test was used to calculate a $p$-value determining the top statistically significant biological functions assigned to the data set.

\section{Real-time quantitative PCR (qPCR)}

Total RNA (750 ng) was subjected to reverse transcription reaction to synthetize cDNA using oligo dT, RNase Out and M-MLV RT enzyme (Life Technologies, ThermoFisher Scientific) according to the manufacturer's instructions.

Real time qPCR experiments were carried out with the 7500 Fast real-Time PCR system (Applied Biosystems, ThermoFisher Scientific), using TaqMan ${ }^{\circledR}$ Fast Universal PCR Master Mix (2X) and the following TaqMan ${ }^{\circ}$ Gene Expression Assays: Oxt (Mm00726655_s1), Avp (Mm00 437761_g1), Lcn2 (Mm01324470_m1), Ptgs2 (Mm00478 374_m1), Esr1 (Mm00433149_m1), Igf1 (Mm004395 60_m1), Gapdh (Mm99999915_g1). Experiments used $7.5 \mathrm{ng}$ of previously prepared cDNA and samples were run in triplicates on six different biological samples for each group. Relative expression levels were determined according to the $\Delta \Delta \mathrm{Ct}$ method where the expression level of the mRNA of interest is given by $2^{-\Delta \Delta C T}$ where $\Delta \Delta C \mathrm{C}=\Delta \mathrm{CT}$ target mRNA $-\triangle \mathrm{CT}$ reference mRNA (Gapdh) in the same sample as previously described $[4,128]$. 


\section{Statistical analysis}

Significant differences between groups were determined using the Kaleida Graph software. We used one-way ANOVA followed by a post-hoc Bonferroni test for multiple comparisons. Kruskal-Wallis test was used to compare two experimental groups. Values represent the mean \pm SEM of the indicated number of independent experiments/animals, and the level of significance was set for $p<0.05^{*}$ or $p<0,01^{* * *}$.

\section{Additional files}

Additional file 1: Table S1. List of vitamin D-related transcripts dysregulated in transgenic 5XFAD mice. Dysregulated transcripts in the adult brain of 9 month-old 5XFAD transgenic female mice in comparison with wild type mice. The acronym and the full name of each gene are indicated. Genes with a VDRE are highlighted in grey. (PDF $117 \mathrm{~kb}$ )

Additional file 2: Comparative analysis of DEGs between different conditions. Table S2. Common DEGs between cortex and hippocampus in Wt mice supplemented with vitamin D3. Table S3. Specific DEGs in cortex of Wt mice supplemented with vitamin D3. Table S4. Specific DEGs in hippocampus of Wt mice supplemented with vitamin D3. Table S5. Common DEGs between cortex and hippocampus in Tg mice supplemented with vitamin D3. Table S6. Specific DEGs in cortex of Tg mice supplemented with vitamin D3. Table S7. Specific DEGs in hippocampus of Tg mice supplemented with vitamin D3. Table S8. Common DEGs between cortex and hippocampus of both Wt and Tg mice supplemented with vitamin D3. (XLSX $214 \mathrm{~kb}$ )

Additional file 3: Table S9. Common DEGs in at least 3 out 4 conditions (cortex; hippocampus; WtVitD; TgVitD). (XLSX 61 kb)

Additional file 4: List of canonical pathways modified by a vitamin D3-enriched diet in Wt and Tg animals. Table S10. Common canonical pathways between Wt and Tg mice supplemented with vitamin D3 and associated DEGs. Table S11. Canonical pathways specifically modified in Wt VitD animals. Table S12. Canonical pathways specifically modified in Tg VitD animals. (XLSX $67 \mathrm{~kb}$ )

Additional file 5: List of DEGs known to be related to vitamin $D$ action in the corertx and hippocampus of Wt and Tg mice. Genes containing a VDRE sequence are highlighted in grey. Table S13. Vitamin D related DEGs in Tg Cont, Tg VitD and Wt VitD mice. Table S14. Common vitamin D related DEGS between Tg Cont and TgVitD or between Tg Cont and Wt VitD. Table S15. Common vitamin D related DEGs between Tg Cont, Tg VitD and Wt VitD mice. (XLSX $95 \mathrm{~kb}$ )

Additional file 6: Figure S1. Comparison of the different DEGs affected in the Wnt/ $\beta$-catenin signaling pathway according to mouse genotype (Wt VitD versus Tg VitD). (PDF $219 \mathrm{~kb}$ )

\section{Abbreviations \\ 1,25(OH)2D3: 1,25-dihydroxycholecalciferol or calcitriol; 25(OH)D: 25- hydroxyvitamin D or calcidiol; 5XFAD: 5 mutations of familial Alzheimer's disease; AD: Alzheimer's disease; APP: amyloid precursor protein; AB: amyloid beta peptide; BBB: blood brain barrier; DEG: differentially expressed genes; ESR1: estrogen receptor 1; FC: fold change; IGF1: insulin growth factor 1; IPA: ingenuity pathway analysis; KO: knock-out; M4; M6; M9: month 4; month 6; month 9; MWM: Morris water maze; PSEN1: presenilin 1; RAWM: radial arm water maze; RXR: retinoid $X$ receptor; TG: transgenic; VDR: vitamin $D$ receptor; VDRE: vitamin D responsive element; VitD: vitamin D; WT: wild type.}

\section{Competing interests}

The authors declare that they have no competing interests

\section{Authors' contributions}

VL performed the experiments and wrote the manuscript. PM participated in interpreting the data and helped draft the manuscript. KB bred and genotyped the mice and helped draft the manuscript. BL performed the microarray assay and helped draft the manuscript. FF designed, and coordinated the study, wrote the manuscript. All authors read and approved the final manuscript.

\section{Acknowledgments}

Aurélia Cès for her help with the behavioral experiments and Philippe

Benech for his input in analyzing the transcriptomic data.

This work was supported by public [Aix-Marseille Université (AMU), Centre National de la Recherche Scientifique (CNRS)] and private grants [Fondation de I'Avenir, Demain Debout, Combattre la Paralysie]. KB was granted a research associate fellowship by the French "Fondation Plan Alzheimer" and A*MIDEX (Management of talents).

\section{Author details}

${ }^{1}$ Aix Marseille Université, CNRS, NICN UMR 7259, Marseille 13916, France. ${ }^{2}$ APHP, Groupe hospitalier universitaire Saint Louis-Lariboisière-Fernand Widal, Centre Mémoire de Ressources et de Recherche, Hôpital Fernand Widal, Paris, France. ${ }^{3}$ Aix Marseille Université, INSERM UMR 1090, TAGC, Marseille, France, Marseille 13288, France.

Received: 25 September 2015 Accepted: 23 February 2016

Published online: 01 March 2016

\section{References}

1. Bateman R. Alzheimer's disease and other dementias: advances in 2014. Lancet Neurol. 2015;14:4-6.

2. Oakley H, Cole SL, Logan S, Maus E, Shao P, Craft J, Guillozet-Bongaarts A, Ohno M, Disterhoft J, Van Eldik L, Berry R, Vassar R. Intraneuronal betaamyloid aggregates, neurodegeneration, and neuron loss in transgenic mice with five familial Alzheimer's disease mutations: potential factors in amyloid plaque formation. J Neurosci Off J Soc Neurosci. 2006;26:10129-40.

3. Webster SJ, Bachstetter AD, Nelson PT, Schmitt FA, Van Eldik LJ. Using mice to model Alzheimer's dementia: an overview of the clinical disease and the preclinical behavioral changes in 10 mouse models. Front Genet. 2014;5:88.

4. Landel V, Baranger K, Virard I, Loriod B, Khrestchatisky M, Rivera S, Benech P, Féron F. Temporal gene profiling of the 5XFAD transgenic mouse model highlights the importance of microglial activation in Alzheimer's disease. Mol Neurodegener. 2014;9:33.

5. Christakos S, Dhawan P, Liu Y, Peng X, Porta A. New insights into the mechanisms of vitamin D action. J Cell Biochem. 2003;88:695-705.

6. Wang T-T, Tavera-Mendoza LE, Laperriere D, Libby E, MacLeod NB, Nagai Y, Bourdeau V, Konstorum A, Lallemant B, Zhang R, Mader S, White JH. Largescale in silico and microarray-based identification of direct 1,25dihydroxyvitamin D3 target genes. Mol Endocrinol. 2005;19:2685-95.

7. Przybelski R, Agrawal S, Krueger D, Engelke JA, Walbrun F, Binkley N. Rapid correction of low vitamin D status in nursing home residents. Osteoporos Int. 2008;19:1621-8.

8. Anastasiou CA, Yannakoulia M, Scarmeas N. Vitamin D and cognition: an update of the current evidence. J Alzheimers Dis. 2014:42 Suppl 3:S71-80.

9. Sato Y, Asoh T, Oizumi K. High prevalence of vitamin D deficiency and reduced bone mass in elderly women with Alzheimer's disease. Bone. 1998;23:555-7.

10. Evatt ML, Delong MR, Khazai N, Rosen A, Triche S, Tangpricha V. Prevalence of vitamin d insufficiency in patients with Parkinson disease and Alzheimer disease. Arch Neurol. 2008;65:1348-52.

11. Annweiler C, Maby E, Meyerber M, Beauchet O. Hypovitaminosis D and executive dysfunction in older adults with memory complaint: a memory clinic-based study. Dement Geriatr Cogn Disord. 2014;37:286-93.

12. Annweiler C, Rolland Y, Schott AM, Blain H, Vellas B, Beauchet O. Serum vitamin $D$ deficiency as a predictor of incident non-Alzheimer dementias: a 7-year longitudinal study. Dement Geriatr Cogn Disord. 2011;32:273-8.

13. Littlejohns TJ, Henley WE, Lang IA, Annweiler C, Beauchet O, Chaves PHM, Fried L, Kestenbaum BR, Kuller LH, Langa KM, Lopez OL, Kos K, Soni M, Llewellyn DJ. Vitamin D and the risk of dementia and Alzheimer disease. Neurology. 2014;83:920-8.

14. Gezen-Ak D, Dursun E, Ertan T, Hanagasi H, Gurvit H, Emre M, Eker E, Ozturk M, Engin F, Yilmazer S. Association between vitamin D receptor gene polymorphism and Alzheimer's disease. Tohoku J Exp Med. 2007;212:275-82

15. Kuningas M, Mooijaart SP, Jolles J, Slagboom PE, Westendorp RG, van Heemst D. VDR gene variants associate with cognitive function and depressive symptoms in old age. Neurobiol Aging. 2009;30:466-73. 
16. Lehmann DJ, Refsum H, Warden DR, Medway C, Wilcock GK, Smith AD. The vitamin D receptor gene is associated with Alzheimer's disease. Neurosci Lett. 2011;504:79-82.

17. Gezen-Ak D, Dursun E, Bilgic B, Hanagasi H, Ertan T, Gurvit H, Emre M, Eker $E$, Ulutin $T$, Uysal O, Yilmazer $S$. Vitamin D receptor gene haplotype is associated with late-onset Alzheimer's disease. Tohoku J Exp Med. 2012;228:189-96

18. Wang L, Hara K, Van Baaren JM, Price JC, Beecham GW, Gallins PJ, Whitehead PL, Wang G, Lu C, Slifer MA, Zuchner S, Martin ER, Mash D, Haines JL, Pericak-Vance MA, Gilbert JR. Vitamin D receptor and Alzheimer's disease: a genetic and functional study. Neurobiol Aging. 2012;1844(33):e1-9.

19. Laczmanski L, Jakubik M, Bednarek-Tupikowska G, Rymaszewska J, Sloka N, Lwow F. Vitamin D receptor gene polymorphisms in Alzheimer's disease patients. Exp Gerontol. 2015;69:142-7.

20. Sutherland MK, Somerville MJ, Yoong LK, Bergeron C, Haussler MR, McLachlan DR. Reduction of vitamin D hormone receptor mRNA levels in Alzheimer as compared to Huntington hippocampus: correlation with calbindin-28k mRNA levels. Brain Res Mol Brain Res. 1992;13:239-50.

21. Ito S, Ohtsuki S, Nezu Y, Koitabashi Y, Murata S, Terasaki T. 1alpha,25Dihydroxyvitamin D3 enhances cerebral clearance of human amyloid-beta peptide(1-40) from mouse brain across the blood-brain barrier. Fluids Barriers CNS. 2011;8:20.

22. Dursun E, Gezen-Ak D, Yilmazer S. A novel perspective for Alzheimer's disease: vitamin $D$ receptor suppression by amyloid-beta and preventing the amyloid-beta induced alterations by vitamin D in cortical neurons. J Alzheimers Dis. 2011;23:207-19.

23. Gezen-Ak D, Dursun E, Yilmazer $\mathrm{S}$. The effects of vitamin D receptor silencing on the expression of LVSCC-A1C and LVSCC-A1D and the release of NGF in cortical neurons. PLoS One. 2011;6:e17553.

24. Taghizadeh M, Djazayery A, Salami M, Eshraghian MR, Zavareh SA. VitaminD-free regimen intensifies the spatial learning deficit in Alzheimer's disease. Int J Neurosci. 2011;121:16-24.

25. Grimm MO, Lehmann J, Mett J, Zimmer VC, Grosgen S, Stahlmann CP, Hundsdorfer B, Haupenthal VJ, Rothhaar TL, Herr C, Bals R, Grimm HS, Hartmann T. Impact of Vitamin D on amyloid precursor protein processing and amyloid-beta peptide degradation in Alzheimer's disease. Neurodegener Dis. 2014;13:75-81.

26. Yu J, Gattoni-Celli M, Zhu H, Bhat NR, Sambamurti K, Gattoni-Celli S, Kindy MS. Vitamin D3-enriched diet correlates with a decrease of amyloid plaques in the brain of AbetaPP transgenic mice. J Alzheimers Dis. 2011;25:295-307.

27. Eyles D, Almeras L, Benech P, Patatian A, Mackay-Sim A, McGrath J, Feron F. Developmental vitamin $D$ deficiency alters the expression of genes encoding mitochondrial, cytoskeletal and synaptic proteins in the adult rat brain. J Steroid Biochem Mol Biol. 2007;103:538-45.

28. Nissou MF, Brocard J, El Atifi M, Guttin A, Andrieux A, Berger F, Issartel JP, Wion D. The transcriptomic response of mixed neuron-glial cell cultures to 1,25-dihydroxyvitamin d3 includes genes limiting the progression of neurodegenerative diseases. J Alzheimers Dis. 2013;35:553-64.

29. Nissou MF, Guttin A, Zenga C, Berger F, Issartel JP, Wion D. Additional clues for a protective role of vitamin $D$ in neurodegenerative diseases: 1,25dihydroxyvitamin D3 triggers an anti-inflammatory response in brain pericytes. J Alzheimers Dis. 2014;42:789-99.

30. Latimer CS, Brewer LD, Searcy JL, Chen KC, Popovic J, Kraner SD, Thibault O, Blalock EM, Landfield PW, Porter NM. Vitamin D prevents cognitive decline and enhances hippocampal synaptic function in aging rats. Proc Natl Acad Sci U S A. 2014;111:E4359-66.

31. Kaneko I, Sabir MS, Dussik CM, Whitfield GK, Karrys A, Hsieh J-C, Haussler MR, Meyer MB, Pike JW, Jurutka PW. 1,25-Dihydroxyvitamin D regulates expression of the tryptophan hydroxylase 2 and leptin genes: implication for behavioral influences of vitamin D. FASEB J Off Publ Fed Am Soc Exp Biol. 2015;29:4023-35.

32. Hawes JE, Tesic D, Whitehouse AJ, Zosky GR, Smith JT, Wyrwoll CS. Materna vitamin $D$ deficiency alters fetal brain development in the BALB/C mouse. Behav Brain Res. 2015;286:192-200.

33. Carlberg C. Genome-wide (over)view on the actions of vitamin D. Front Physiol. 2014:5:167.

34. de Abreu Fernandes DA, Eyles D, Feron F. Vitamin D, a neuro-immunomodulator: implications for neurodegenerative and autoimmune diseases. Psychoneuroendocrinology. 2009;34 Suppl 1:S265-77.
35. Yin K, Agrawal DK. Vitamin D and inflammatory diseases. J Inflamm Res. 2014;7:69-87.

36. Lemire JM, Archer DC, Beck L, Spiegelberg HL. Immunosuppressive actions of 1,25-dihydroxyvitamin D3: preferential inhibition of Th1 functions. J Nutr. 1995;125(6 Suppl):1704S-8S.

37. Boonstra A, Barrat FJ, Crain C, Heath VL, Savelkoul HF, O'Garra A. 1alpha,25Dihydroxyvitamin $\mathrm{d} 3$ has a direct effect on naive CD4(+) T cells to enhance the development of Th2 cells. J Immunol. 2001;167:4974-80.

38. Cantorna MT, Waddell A. The vitamin D receptor turns off chronically activated T cells. Ann N Y Acad Sci. 2014;1317:70-5.

39. Hewison M. Vitamin $D$ and the immune system: new perspectives on an old theme. Rheum Dis Clin North Am. 2012;38:125-39.

40. Jeffery LE, Burke F, Mura M, Zheng Y, Qureshi OS, Hewison M, Walker LSK, Lammas DA, Raza K, Sansom DM. 1,25-Dihydroxyvitamin D3 and IL-2 combine to inhibit $\mathrm{T}$ cell production of inflammatory cytokines and promote development of regulatory T cells expressing CTLA-4 and FoxP3. J Immunol. 2009;183:5458-67.

41. Ryynänen J, Carlberg C. Primary 1,25-dihydroxyvitamin D3 response of the interleukin 8 gene cluster in human monocyte- and macrophage-like cells. PLoS One. 2013;8:e78170.

42. Campbell MJ. Vitamin D and the RNA transcriptome: more than mRNA regulation. Front Physiol. 2014;5:181.

43. Nanduri R, Mahajan S, Bhagyaraj E, Sethi K, Kalra R, Chandra V, Gupta P. The Active Form of Vitamin D Transcriptionally Represses Smad7 Signaling and Activates Extracellular Signal-regulated Kinase (ERK) to Inhibit the Differentiation of a Inflammatory T Helper Cell Subset and Suppress Experimental Autoimmune Encephalomyelitis. J Biol Chem. 2015;290:12222-36.

44. Chen Y, Liu W, Sun T, Huang Y, Wang Y, Deb DK, Yoon D, Kong J, Thadhani R, Li YC 1,25-Dihydroxyvitamin D Promotes Negative Feedback Regulation of TollLike Receptor Signaling via Targeting MicroRNA-155-SOCS1 in Macrophages. J Immunol. 2013;190:3687-95.

45. Li YC, Chen Y, Liu W, Thadhani R. MicroRNA-mediated mechanism of vitamin $D$ regulation of innate immune response. J Steroid Biochem Mol Biol. 2014;144(Pt A):81-6.

46. Wöbke TK, Sorg BL, Steinhilber D. Vitamin D in inflammatory diseases. Front Physiol. 2014;5:244.

47. Barnes PJ. Anti-inflammatory actions of glucocorticoids: molecular mechanisms. Clin Sci (Lond). 1998;94:557-72.

48. Müller MR, Rao A. NFAT, immunity and cancer: a transcription factor comes of age. Nat Rev Immunol. 2010;10:645-56.

49. Joshi S, Pantalena L-C, Liu XK, Gaffen SL, Liu H, Rohowsky-Kochan C, Ichiyama K, Yoshimura A, Steinman L, Christakos S, Youssef S. 1,25dihydroxyvitamin D(3) ameliorates Th17 autoimmunity via transcriptional modulation of interleukin-17A. Mol Cell Biol. 2011:31:3653-69.

50. Cohen-Lahav M, Shany S, Tobvin D, Chaimovitz C, Douvdevani A. Vitamin D decreases NFKB activity by increasing IKBa levels. Nephrol Dial Transplant. 2006:21:889-97.

51. Harant H, Wolff B, Lindley IJD. 1a,25-Dihydroxyvitamin D3 decreases DNA binding of nuclear factor-KB in human fibroblasts. FEBS Lett. 1998;436:329-34.

52. Fekrmandi F, Wang T-T, White $J H$. The hormone-bound vitamin D receptor enhances the FBW7-dependent turnover of NF-kB subunits. Sci Rep. 2015;5:13002.

53. Tsatsanis C, Androulidaki A, Venihaki M, Margioris AN. Signalling networks regulating cyclooxygenase-2. Int J Biochem Cell Biol. 2006;38:1654-61.

54. DeLuca GC, Kimball SM, Kolasinski J, Ramagopalan SV, Ebers GC. Review: the role of vitamin D in nervous system health and disease. Neuropathol Appl Neurobiol. 2013;39:458-84.

55. de Viragh PA, Haglid KG, Celio MR. Parvalbumin increases in the caudate putamen of rats with vitamin D hypervitaminosis. Proc Natl Acad Sci U S A. 1989;86:3887-90.

56. Garcion E, Nataf S, Berod A, Darcy F, Brachet P. 1,25-Dihydroxyvitamin D3 inhibits the expression of inducible nitric oxide synthase in rat central nervous system during experimental allergic encephalomyelitis. Brain Res Mol Brain Res. 1997:45:255-67.

57. Féron F, Burne THJ, Brown J, Smith E, McGrath JJ, Mackay-Sim A, Eyles DW Developmental Vitamin D3 deficiency alters the adult rat brain. Brain Res Bull. 2005;65:141-8.

58. Almeras L, Eyles D, Benech P, Laffite D, Villard C, Patatian A, Boucraut J, Mackay-Sim A, McGrath J, Feron F. Developmental vitamin D deficiency alters brain protein expression in the adult rat: implications for neuropsychiatric disorders. Proteomics. 2007;7:769-80. 
59. McGrath JJ, Féron FP, Burne TH, Mackay-Sim A, Eyles DW. Vitamin D3implications for brain development. J Steroid Biochem Mol Biol. 2004;8990(1-5):557-60.

60. Cui X, Gooch H, Groves NJ, Sah P, Burne TH, Eyles DW, McGrath JJ. Vitamin $\mathrm{D}$ and the brain: key questions for future research. J Steroid Biochem Mol Biol. 2015;148:305-9.

61. Tabata T, Shoji T, Kikunami K, Matsushita Y, Inoue T, Tanaka S, Hino M, Miki T, Nishizawa Y, Morii H. In vivo effect of 1 alpha-hydroxyvitamin D3 on interleukin-2 production in hemodialysis patients. Nephron. 1988;50:295-8.

62. Di Rosa M, Malaguarnera G, De Gregorio C, Palumbo M, Nunnari G, Malaguarnera L. Immuno-modulatory effects of vitamin D3 in human monocyte and macrophages. Cell Immunol. 2012;280:36-43.

63. Bouter $Y$, Kacprowski T, Weissmann R, Dietrich K, Borgers H, Brauß A, Sperling C, Wirths O, Albrecht M, Jensen LR, Kuss AW, Bayer TA. Deciphering the molecular profile of plaques, memory decline and neuron loss in two mouse models for Alzheimer's disease by deep sequencing. Front Aging Neurosci. 2014;6:75.

64. Berridge MJ. Vitamin D: a custodian of cell signalling stability in health and disease. Biochem Soc Trans. 2015;43:349-58.

65. Larriba MJ, González-Sancho JM, Bonilla F, Muñoz A. Interaction of vitamin D with membrane-based signaling pathways. Front Physiol. 2014:5:60

66. Bilkei-Gorzo A. Genetic mouse models of brain ageing and Alzheimer's disease. Pharmacol Ther. 2014;142:244-57.

67. Pollio G, Hoozemans JJM, Andersen CA, Roncarati R, Rosi MC, van Haastert ES, Seredenina T, Diamanti D, Gotta S, Fiorentini A, Magnoni L, Raggiaschi R, Rozemuller AJM, Casamenti F, Caricasole A, Terstappen GC. Increased expression of the oligopeptidase THOP1 is a neuroprotective response to Abeta toxicity. Neurobiol Dis. 2008;31:145-58.

68. Dougherty U, Mustafi R, Sadiq F, Almoghrabi A, Mustafi D, Kreisheh M, Sundaramurthy S, Liu W, Konda VJ, Pekow J, Khare S, Hart J, Joseph L, Wyrwicz A, Karczmar GS, Li YC, Bissonnette M. The renin-angiotensin system mediates EGF receptor-vitamin d receptor cross-talk in colitis-associated colon cancer. Clin Cancer Res. 2014;20:5848-59.

69. Carson JA, Turner AJ. Beta-amyloid catabolism: roles for neprilysin (NEP) and other metallopeptidases? J Neurochem. 2002;81:1-8.

70. Hemming ML, Selkoe DJ. Amyloid beta-protein is degraded by cellular angiotensin-converting enzyme (ACE) and elevated by an ACE inhibitor. J Biol Chem. 2005;280:37644-50.

71. Zou K, Yamaguchi H, Akatsu H, Sakamoto T, Ko M, Mizoguchi K, Gong J-S, Yu W, Yamamoto T, Kosaka K, Yanagisawa K, Michikawa M. Angiotensinconverting enzyme converts amyloid beta-protein 1-42 (Abeta(1-42)) to Abeta(1-40), and its inhibition enhances brain Abeta deposition. J Neurosci Off J Soc Neurosci. 2007;27:8628-35.

72. Carter CJ. Convergence of genes implicated in Alzheimer's disease on the cerebral cholesterol shuttle: APP, cholesterol, lipoproteins, and atherosclerosis. Neurochem Int. 2007;50:12-38.

73. Di Marco LY, Venneri A, Farkas E, Evans PC, Marzo A, Frangi AF. Vascular dysfunction in the pathogenesis of Alzheimer's disease - A review of endothelium-mediated mechanisms and ensuing vicious circles. Neurobiol Dis. 2015;82:593-606.

74. Giau W, Bagyinszky E, An SSA, Kim SY. Role of apolipoprotein E in neurodegenerative diseases. Neuropsychiatr Dis Treat. 2015;11:1723-37.

75. Lange CM, Gouttenoire J, Duong FHT, Morikawa K, Heim MH, Moradpour D. Vitamin D receptor and Jak-STAT signaling crosstalk results in calcitriolmediated increase of hepatocellular response to IFN-a. J Immunol. 2014;192:6037-44

76. Trusca VG, Fuior EV, Florea IC, Kardassis D, Simionescu M, Gafencu AV. Macrophage-specific up-regulation of apolipoprotein $\mathrm{E}$ gene expression by STAT1 is achieved via long range genomic interactions. J Biol Chem. 2011;286:13891-904

77. Wang JM, Irwin RW, Brinton RD. Activation of estrogen receptor alpha increases and estrogen receptor beta decreases apolipoprotein $\mathrm{E}$ expression in hippocampus in vitro and in vivo. Proc Natl Acad Sci U S A. 2006;103:16983-8.

78. Maddock J, Cavadino A, Power C, Hyppönen E. 25-hydroxyvitamin D, APOE $\varepsilon 4$ genotype and cognitive function: findings from the 1958 British birth cohort. Eur J Clin Nutr. 2015;69:505-8.

79. Gezen-Ak D, Yilmazer S, Dursun E. Why vitamin D in Alzheimer's disease? The hypothesis. J Alzheimers Dis. 2014;40:257-69.

80. Yanagisawa J, Yanagi Y, Masuhiro Y, Suzawa M, Watanabe M, Kashiwagi K, Toriyabe T, Kawabata M, Miyazono K, Kato S. Convergence of transforming growth factor-beta and vitamin D signaling pathways on SMAD transcriptional coactivators. Science. 1999;283:1317-21.

81. Lesné S, Docagne F, Gabriel C, Liot G, Lahiri DK, Buée L, Plawinski L, Delacourte A, MacKenzie ET, Buisson A, Vivien D. Transforming growth factor-beta 1 potentiates amyloid-beta generation in astrocytes and in transgenic mice. J Biol Chem. 2003;278:18408-18.

82. Biegon A, Terlou M, Voorhuis TD, de Kloet ER. Arginine-vasopressin binding sites in rat brain: a quantitative autoradiographic study. Neurosci Lett. 1984;44:229-34

83. Boccia ML, Petrusz P, Suzuki K, Marson L, Pedersen CA. Immunohistochemical localization of oxytocin receptors in human brain. Neuroscience. 2013;253:155-64.

84. Kim T-K, Lee J-E, Kim J-E, Park J-Y, Choi J, Kim H, Lee E-H, Han P-L: G9aMediated Regulation of OXT and AVP Expression in the Basolateral Amygdala Mediates Stress-Induced Lasting Behavioral Depression and Its Reversal by Exercise. Mol Neurobiol 2015. Epub ahead of print.

85. Metzger D, Alescio-Lautier B, Soumireu-Mourat B. Facilitation of retention performance in mice by pretest microinjection of AVP into dorsal or ventral hippocampus: differential influence of the peptide on appetitive task. Neurosci Lett. 1989;101:77-82.

86. Sato T, Tanaka K, Teramoto T, Ohnishi Y, Hirate K, Irifune M, Nishikawa T. Facilitative effect of a novel AVP fragment analog, NC-1900, on memory retention and recall in mice. Peptides. 2004;25:1139-46.

87. Fujiyoshi K, Suga H, Okamoto K, Nakamura S, Kameyama M. Reduction of arginine-vasopressin in the cerebral cortex in Alzheimer type senile dementia. J Neurol Neurosurg Psychiatry. 1987;50:929-32.

88. Perras B, Wagner U, Born J, Fehm HL. Improvement of sleep and pituitaryadrenal inhibition after subchronic intranasal vasopressin treatment in elderly humans. J Clin Psychopharmacol. 2003;23:35-44.

89. Jing W, Guo F, Cheng L, Zhang J-F, Qi J-S. Arginine vasopressin prevents amyloid beta protein-induced impairment of long-term potentiation in rat hippocampus in vivo. Neurosci Lett. 2009;450:306-10.

90. Pan Y-F, Chen X-R, Wu M-N, Ma C-G, Qi J-S. Arginine vasopressin prevents against Abeta(25-35)-induced impairment of spatial learning and memory in rats. Horm Behav. 2010;57:448-54.

91. Lin Y-T, Huang C-C, Hsu K-S. Oxytocin promotes long-term potentiation by enhancing epidermal growth factor receptor-mediated local translation of protein kinase MC. J Neurosci Off J Soc Neurosci. 2012;32:15476-88.

92. Hu J, Qi S, Becker B, Luo L, Gao S, Gong Q, Hurlemann R, Kendrick KM. Oxytocin selectively facilitates learning with social feedback and increases activity and functional connectivity in emotional memory and reward processing regions. Hum Brain Mapp. 2015;36:2132-46.

93. Wang $Y$, Zhao S, Wu Z, Feng Y, Zhao C, Zhang C. Oxytocin in the regulation of social behaviours in medial amygdala-lesioned mice via the inhibition of the extracellular signal-regulated kinase signalling pathway. Clin Exp Pharmacol Physiol. 2015;42:465-74.

94. Naudé PJW, Nyakas C, Eiden LE, Ait-Ali D, van der Heide R, Engelborghs S, Luiten PGM, De Deyn PP, Boer JA den, Eisel ULM. Lipocalin 2: novel component of proinflammatory signaling in Alzheimer's disease. FASEB J. 2012;26:2811-23.

95. Mesquita SD, Ferreira AC, Falcao AM, Sousa JC, Oliveira TG, Correia-Neves M, Sousa N, Marques F, Palha JA. Lipocalin 2 modulates the cellular response to amyloid beta. Cell Death Differ. 2014;21:1588-99.

96. Kinuta K, Tanaka H, Moriwake T, Aya K, Kato S, Seino Y. Vitamin D is an important factor in estrogen biosynthesis of both female and male gonads. Endocrinology. 2000;141:1317-24.

97. Swami S, Krishnan AV, Wang JY, Jensen K, Peng L, Albertelli MA, Feldman D. Inhibitory effects of calcitriol on the growth of MCF-7 breast cancer xenografts in nude mice: selective modulation of aromatase expression in vivo. Horm Cancer. 2011;2:190-202.

98. Katzburg S, Hendel D, Waisman A, Posner GH, Kaye AM, Somjen D. Treatment with non-hypercalcemic analogs of 1,25-dihydroxyvitamin D3 increases responsiveness to 17 beta-estradiol, dihydrotestosterone or raloxifene in primary human osteoblasts. J Steroid Biochem Mol Biol. 2004;88:213-9.

99. Jorm AF, Korten AE, Henderson AS. The prevalence of dementia: a quantitative integration of the literature. Acta Psychiatr Scand. 1987;76:465-79.

100. Henderson WW, Paganini-Hill A, Emanuel CK, Dunn ME, Buckwalter JG. Estrogen replacement therapy in older women. Comparisons between Alzheimer's disease cases and nondemented control subjects. Arch Neurol. 1994;51:896-900.

101. Liu S, Zhao M. Neuroprotective effect of estrogen: role of nonsynaptic NR2B-containing NMDA receptors. Brain Res Bull. 2013;93:27-31. 
102. Lan Y-L, Zhao J, Li S. Update on the neuroprotective effect of estrogen receptor alpha against Alzheimer's disease. J Alzheimers Dis. 2015;43:1137-48.

103. Shi C, Zhu X, Wang J, Long D. Estrogen receptor a promotes nonamyloidogenic processing of platelet amyloid precursor protein via the MAPKJERK pathway. J Steroid Biochem Mol Biol. 2014;144(Pt B):280-5.

104. Swami S, Krishnan AV, Peng L, Lundqvist J, Feldman D. Transrepression of the estrogen receptor promoter by calcitriol in human breast cancer cells via two negative vitamin D response elements. Endocr Relat Cancer. 2013;20:565-77

105. Mendez P, Azcoitia I, Garcia-Segura LM. Estrogen receptor alpha forms estrogen-dependent multimolecular complexes with insulin-like growth factor receptor and phosphatidylinositol 3-kinase in the adult rat brain. Brain Res Mol Brain Res. 2003;112:170-6.

106. Chen W-F, Zhou L-P, Chen L, Wu L, Gao Q-G, Wong M-S. Involvement of IGF-I receptor and estrogen receptor pathways in the protective effects of ginsenoside Rg1 against A $\beta_{25-35}$-induced toxicity in PC12 cells. Neurochem Int. 2013;62:1065-71.

107. Taguchi A, White MF. Insulin-like signaling, nutrient homeostasis, and life span. Annu Rev Physiol. 2008;70:191-212.

108. Rozing MP, Westendorp RGJ, Frölich M, de Craen AJM, Beekman M, Heijmans BT, Mooijaart SP, Blauw G-J, Slagboom PE, van Heemst D, Leiden Longevity Study (LLS) Group. Human insulin/IGF-1 and familial longevity at middle age. Aging. 2009;1:714-22.

109. Moloney AM, Griffin RJ, Timmons S, O'Connor R, Ravid R, O'Neill C. Defects in IGF-1 receptor, insulin receptor and IRS-1/2 in Alzheimer's disease indicate possible resistance to IGF-1 and insulin signalling. Neurobiol Aging. 2010;31:224-43.

110. Freude S, Schilbach K, Schubert M. The role of IGF-1 receptor and insulin receptor signaling for the pathogenesis of Alzheimer's disease: from model organisms to human disease. Curr Alzheimer Res. 2009;6:213-23.

111. Gontier G, George C, Chaker Z, Holzenberger M, Aïd S. Blocking IGF Signaling in Adult Neurons Alleviates Alzheimer's Disease Pathology through Amyloid- $\beta$ Clearance. J Neurosci Off J Soc Neurosci. 2015;35:11500-13.

112. Keisala T, Minasyan A, Lou YR, Zou J, Kalueff AV, Pyykko I, Tuohimaa P. Premature aging in vitamin D receptor mutant mice. J Steroid Biochem Mol Biol. 2009;115:91-7.

113. Wang Y, Sun Z. Current understanding of klotho. Ageing Res Rev. 2009;8:43-51.

114. Nawashiro H, Messing A, Azzam N, Brenner M. Mice lacking GFAP are hypersensitive to traumatic cerebrospinal injury. Neuroreport. 1998;9:1691-6.

115. Otani N, Nawashiro H, Fukui S, Ooigawa H, Ohsumi A, Toyooka T, Shima K, Gomi H, Brenner M. Enhanced hippocampal neurodegeneration after traumatic or kainate excitotoxicity in GFAP-null mice. J Clin Neurosci. 2006:13:934-8.

116. Kraft AW, Hu X, Yoon H, Yan P, Xiao Q, Wang Y, Gil SC, Brown J, Wilhelmsson U, Restivo JL, Cirrito JR, Holtzman DM, Kim J, Pekny M, Lee J-M. Attenuating astrocyte activation accelerates plaque pathogenesis in APP/ PS1 mice. FASEB J. 2013;27:187-98.

117. Orre M, Kamphuis W, Osborn LM, Jansen AHP, Kooijman L, Bossers K, Hol EM. Isolation of glia from Alzheimer's mice reveals inflammation and dysfunction. Neurobiol Aging. 2014;35:2746-60.

118. Lue LF, Kuo YM, Beach T, Walker DG. Microglia activation and anti-inflammatory regulation in Alzheimer's disease. Mol Neurobiol. 2010;41:115-28.

119. Walker DG, Link J, Lue L-F, Dalsing-Hernandez JE, Boyes BE. Gene expression changes by amyloid beta peptide-stimulated human postmortem brain microglia identify activation of multiple inflammatory processes. J Leukoc Biol. 2006;79:596-610.

120. Qiao D-L, Zhang S-Q, Giunta B. Is Vitamin D Beneficial to Alzheimer Disease? A Surprising Dilemma. CNS Neurosci Ther. 2012;18:601-3.

121. Mizwicki MT, Menegaz D, Zhang J, Barrientos-Duran A, Tse S, Cashman JR, Griffin PR, Fiala M. Genomic and nongenomic signaling induced by 1alpha,25(OH)2-vitamin D3 promotes the recovery of amyloid-beta phagocytosis by Alzheimer's disease macrophages. J Alzheimers Dis. 2012;29:51-62

122. Mizwicki MT, Liu G, Fiala M, Magpantay L, Sayre J, Siani A, Mahanian M, Weitzman R, Hayden EY, Rosenthal MJ, Nemere I, Ringman J, Teplow DB. 1alpha,25-dihydroxyvitamin D3 and resolvin D1 retune the balance between amyloid-beta phagocytosis and inflammation in Alzheimer's disease patients. J Alzheimers Dis. 2013;34:155-70.

123. Durk MR, Han K, Chow EC, Ahrens R, Henderson JT, Fraser PE, Pang KS. 1alpha,25-Dihydroxyvitamin D3 reduces cerebral amyloid-beta accumulation and improves cognition in mouse models of Alzheimer's disease. J Neurosci. 2014:34:7091-101.

124. Bennett L, Kersaitis C, Macaulay SL, Munch G, Niedermayer G, Nigro J, Payne M, Sheean P, Vallotton P, Zabaras D, Bird M. Vitamin D2-enriched button mushroom (Agaricus bisporus) improves memory in both wild type and APPswe/PS1dE9 transgenic mice. PLoS One. 2013;8:e76362.

125. Briones TL, Darwish H. Vitamin D mitigates age-related cognitive decline through the modulation of pro-inflammatory state and decrease in amyloid burden. J Neuroinflammation. 2012;9:244.

126. Briones TL, Darwish H. Decrease in age-related tau hyperphosphorylation and cognitive improvement following vitamin D supplementation are associated with modulation of brain energy metabolism and redox state. Neuroscience. 2014;262:143-55

127. Dimitrov $V$, White $J H$ : Species-specific regulation of innate immunity by vitamin D signaling. J Steroid Biochem Mol Biol. 2015. Epub ahead of print.

128. Py NA, Bonnet AE, Bernard A, Marchalant Y, Charrat E, Checler F, Khrestchatisky M, Baranger K, Rivera S. Differential spatio-temporal regulation of MMPs in the 5xFAD mouse model of Alzheimer's disease: evidence for a pro-amyloidogenic role of MT1-MMP. Front Aging Neurosci. 2014;6:247.

129. Alamed J, Wilcock DM, Diamond DM, Gordon MN, Morgan D. Two-day radial-arm water maze learning and memory task; robust resolution of amyloid-related memory deficits in transgenic mice. Nat Protoc. 2006;1:1671-9.

\section{Submit your next manuscript to BioMed Central and we will help you at every step:}

- We accept pre-submission inquiries

- Our selector tool helps you to find the most relevant journal

- We provide round the clock customer support

- Convenient online submission

- Thorough peer review

- Inclusion in PubMed and all major indexing services

- Maximum visibility for your research

Submit your manuscript at www.biomedcentral.com/submit

) Biomed Central 